\title{
Coercive, enabling, diagnostic, and interactive control: Untangling the threads of their connections
}

\author{
Josep Bisbe * \\ Universitat Ramon Llull, ESADE Business School \\ Avda. Pedralbes, 60-62 \\ 08034 Barcelona, Spain \\ Phone: +34 932806162 \\ josep.bisbe@esade.edu \\ *corresponding author. \\ Anne-Marie Kruis \\ Nyenrode Business University \\ PO Box 130 \\ 3620 AC Breukelen, The Netherlands \\ Phone: +31 346291311 \\ a.kruis@,nyenrode.nl \\ Paola Madini \\ University of Kent, Kent Business School \\ University Road \\ Canterbury, Kent CT2 7PE \\ United Kingdom \\ Phone: +44 1227827557 \\ P.M.Madini@kent.ac.uk
}

Declaration of interest: None

(C) 2019. This manuscript version is made available under the CC-BY-NC-ND 4.0 license http://creativecommons.org/licenses/by-nc-nd/4.0/ 


\title{
Coercive, enabling, diagnostic, and interactive control: Untangling the threads of their connections
}

\begin{abstract}
Recent accounting research has connected the coercive and enabling types of formalisation (C/E) (Adler and Borys, 1996) with the distinction between diagnostic and interactive controls (D/I) proposed by Simons $(1995,2000)$ to tackle research questions on complex control situations involving both the degree of employee autonomy and patterns of management attention. The diverse conceptual approaches used for connecting $\mathrm{C} / \mathrm{E}$ and $\mathrm{D} / \mathrm{I}$ have led to fragmentation in the literature and raise concerns about their conceptual clarity. In this paper, we assess the conceptual clarity of various forms of connection between $\mathrm{C} / \mathrm{E}$ and D/I. Firstly, we conduct an in-depth content analysis of 59 recent papers, and inductively identify three points of conceptual ambiguity and divergence in the literature (namely, the perspective from which a phenomenon is studied; whether categories capture choices driven by design or by style-of-use; and the properties of control systems). We also observe that the literature proposes various forms of connection (i.e. coexistence, inclusion, and combination approaches). Secondly, we use the three detected points of ambiguity and divergence as assessment criteria, and evaluate the extent to which conceptual clarity is at risk under each form of connection. Based on this assessment, we provide guidelines to enhance the conceptual clarity of the connections between $\mathrm{C} / \mathrm{E}$ and $\mathrm{D} / \mathrm{I}$, propose several research models, and indicate opportunities for future research in this area.
\end{abstract}

Keywords: conceptual clarity; enabling; coercive; interactive; diagnostic; control systems.

\section{Introduction}

It is widely recognised in the literature that the implications and outcomes of Management Control Systems (henceforth, MCSs) depend on how organisational members experience their use (Cugueró-Escofet \& Rosanas, 2013; Ferreira \& Otley, 2009; Hall, 2010; Hopwood, 1972, 1973). ${ }^{1}$ Over the past two decades, a significant number of papers examining dimensions related to experienced patterns of use of MCSs have relied on at least one of two predominant theoretical frameworks: Adler and Borys' (1996) typology, which distinguishes between coercive and

\footnotetext{
${ }^{1}$ In this paper, we define MCSs narrowly to incorporate only formal feedback and measurement systems (Chenhall, Hall \& Smith, 2010; Chenhall \& Morris, 1986; Simons, 1995). These formal controls are deliberately articulated practices, routines, and procedures based on financial and/or non-financial information. With the plausible exception of small early-stage firms (Davila \& Foster, 2007; Granlund \& Taipaleenmäki, 2005), in most organisations formal feedback and measurement systems (e.g. budget systems, project management systems, cost accounting systems, balanced scorecards, and other performance measurement systems) represent a substantial subset of the broader control system or control package (Grabner \& Moers, 2013; Malmi \& Brown, 2008; Otley, 1980).
} 
enabling types of bureaucratic formalisation (henceforth, C/E) (e.g. Ahrens \& Chapman, 2004; Englund \& Gerdin, 2015; Free, 2007; Jorgensen \& Messner, 2009; Wouters \& Roijmans, 2011), and Simons' $(1995,2000)$ levers of control framework (LOC), which distinguishes diagnostic and interactive control systems (henceforth, D/I) (e.g. Bedford, 2015; Bisbe \& Otley, 2004; Gond, Grubnic, Herzig \& Moon, 2012; Henri, 2006; Naranjo-Gil \& Hartmann, 2007; Su, Baird \& Schoch, 2015; Widener, 2007). ${ }^{2}$

As the categorisations of controls in $\mathrm{C} / \mathrm{E}$ and $\mathrm{D} / \mathrm{I}$ have taken hold, an emerging stream of literature has found it fruitful to connect them. Thus, out of 59 reviewed studies on MCSs published in the period 1995-2015 that draw on C/E or D/I, 23 refer conjointly to both categorisations, or are at least informed by them. Researchers have relied on the connection between $\mathrm{C} / \mathrm{E}$ and $\mathrm{D} / \mathrm{I}$ to examine how MCSs influence aspects of organisational life: such as the ability to implement strategies (Naranjo-Gil \& Hartmann, 2006); the development of social capital (Chenhall, Hall \& Smith, 2010); and the motivational underpinnings of large-scale collaborative creativity (Adler \& Chen, 2011). Studies in this stream have simultaneously drawn on those categorisations expecting that the connection between them helps make sense of complex management control situations. These studies suggest that connecting $\mathrm{C} / \mathrm{E}$ and $\mathrm{D} / \mathrm{I}$ is a potentially productive strategy to further our understanding of the workings of MCSs, since each categorisation by itself provides only a partial and insufficient explanation.

Despite this potential, it has yet to be resolved how the connection between $\mathrm{C} / \mathrm{E}$ and $\mathrm{D} / \mathrm{I}$ should be conceptualised. Some studies suggest that $\mathrm{C} / \mathrm{E}$ and $\mathrm{D} / \mathrm{I}$ draw on different theoretical grounds and look at control practices through different theoretical lenses (e.g. Mahama \& Cheng, 2013; de Yarlez \& Malagueño, 2015). Moreover, considerable diversity surfaces in the ways the two categorisations have been connected in earlier literature. For example, some studies suggest that interactive [diagnostic] control systems are a constitutive component of enabling [coercive] control systems (e.g. Free, 2007), whereas others suggest that control systems designed with enabling or coercive characteristics can be used both in a diagnostic and an interactive manner (e.g. Chenhall et al., 2010). Overall, the available literature connecting $\mathrm{C} / \mathrm{E}$ and $\mathrm{D} / \mathrm{I}$ reveals considerable fragmentation, which threatens conceptual clarity. Lack of conceptual clarity is problematic, for it brings the risk of confusion and contradictions in theory-building, which in turn

\footnotetext{
${ }^{2}$ In addition to diagnostic and interactive control systems, LOC comprises belief systems and boundary systems. Beliefs and boundary systems are formally stated sets of beliefs, rules, or limits that do not constitute feedback and measurement systems. Out of the four levers, only diagnostic and interactive systems refer to forms of feedback and measurement systems that are the object of this study. We refer to the theorisation around diagnostic and interactive systems levers as the D/I categorisation.
} 
hinder the development of a cumulative body of knowledge (Molloy \& Ployhart, 2012; Podsakoff, MacKenzie \& Podsakoff, 2016; Suddaby, 2010).

We believe it is time to untangle the threads of the connections between $\mathrm{C} / \mathrm{E}$ and $\mathrm{D} / \mathrm{I}$ to gain a more holistic understanding of how the implications and outcomes of MCSs are influenced by the ways organisational members experience their use. Within the process of scholarly dialectic between broader encompassing approaches and narrower validity approaches (Hirsch \& Levin, 1999), and acknowledging a dynamic view of conceptualisation (Suddaby, 2010; Molloy \& Ployhart, 2012), we assess how substantive and generalised is the fragmentation in the literature, and to what extent this puts conceptual clarity at risk. Furthermore, we tackle this fragmentation by providing indications on how to improve the conceptual clarity of the connections between $\mathrm{C} / \mathrm{E}$ and D/I. To attain these goals, we first conduct an in-depth analysis of the literature to identify potential sources of lack of such conceptual clarity. We find three critical points that create conceptual ambiguity and divergence in earlier studies (namely, perspective; design-driven versus style-of-use-driven choices; and properties). We further detect considerable divergence in the approaches used to specify the form of connection between $\mathrm{C} / \mathrm{E}$ and $\mathrm{D} / \mathrm{I}$ (i.e. coexistence approach, inclusion approaches, and combinatory approaches). We then examine the literature to assess to what extent the detected points of conceptual ambiguity and divergence pose problems for each of these approaches.

The contribution of this paper is twofold. Firstly, by assessing the extent to which and the conditions under which each approach can effectively deal with the points of ambiguity and divergence, we provide guidelines to enhance conceptual clarity in future accounting research interested in drawing on both $\mathrm{C} / \mathrm{E}$ and $\mathrm{D} / \mathrm{I}$. Secondly, we propose a series of generic research models for different forms of connection between $\mathrm{C} / \mathrm{E}$ and $\mathrm{D} / \mathrm{I}$, illustrating their applicability with a set of research questions. In so doing, we point out some opportunities for conceptually clear research on connecting these categorisations to gain a more holistic understanding of control situations.

The paper is structured as follows. Section 2 examines the importance of conceptual clarity applied to individual constructs, as well as to connections between categorisations. In Section 3, we present a systematic review of the literature on the $\mathrm{C} / \mathrm{E}$ and $\mathrm{D} / \mathrm{I}$ categorisations and briefly introduce the specific criteria that are identified as points of ambiguity and divergence in the literature. Section 4 comprises a detailed discussion of the extent to which these criteria threaten conceptual clarity within categorisations (C/E and D/I separately) and across categorisations. In Section 5, we identify alternative approaches to the form of connection between $\mathrm{C} / \mathrm{E}$ and $\mathrm{D} / \mathrm{I}$, and we examine how the threats to conceptual clarity are manifested in each approach. For each 
approach, we also propose a generic research model and suggest research opportunities. Our conclusions are presented in Section 6.

\section{Conceptual clarity}

Conceptual clarity is needed in both positivist and non-positivist research to effectively provide representations that help make sense of organisational phenomena or situations, and for articulating and communicating statements about them (Ahrens \& Chapman, 2006; Luft \& Shields, 2003; Podsakoff et al., 2016; Suddaby, 2010). Conceptual clarity applied to an individual construct (i.e. construct clarity) refers to how far its conceptual definition is precise and agreed on by scholars in a community. ${ }^{3}$ Construct clarity requires the specification of the necessary and sufficient properties needed to define a phenomenon. Construct clarity is at risk when the definition of a concept does not provide a precise and parsimonious distinction between it and other related concepts, when it is subject to multiple interpretations (i.e. ambiguity), or it presents non-justified discrepancies from prior cumulative knowledge (i.e. divergence) (Hirsch \& Levin, 1999; Mackenzie, Podsakoff \& Podsakoff, 2011; Molloy \& Plohart, 2012). ${ }^{4}$

Likewise, studies interested in connecting theoretical frameworks (e.g. C/E and D/I) should strive for clarity in conceptualising the connection, as a lack of clarity would produce fragmentation, spawn misunderstandings among researchers, and stall scholarly advances. In addition to precise and commonly agreed definitions of the stand-alone categorisations, conceptual clarity regarding the connections between categorisations further refers to how far the form of connection is precise and agreed on by scholars. It further requires clarification of how one's view of the connections builds on (or departs from) depictions adopted in prior literature on each of the categorisations and on their connections. Poor conceptual clarity in the connections between distinct categorisations (e.g. $\mathrm{C} / \mathrm{E}$ and $\mathrm{D} / \mathrm{I}$ ) may stem from three sources. First, underlying

\footnotetext{
${ }^{3}$ For quantitative studies, the quest for construct clarity (i.e., precise conceptual definitions) should precede the quest for construct validity (i.e., correspondence between operational definition and nominal definition) (Molloy \& Ployhart, 2012). In this paper, and in accordance with Suddaby (2010), we adopt the term 'construct' as interchangeable with 'concept' and therefore not necessarily associated with connotations of hypothesis testing or quantitative operationalisation.

${ }^{4}$ As they are applied to new empirical contexts and exposed to new theoretical insights, definitions of concepts are subject to an evolving re-elaboration that is likely to lead them beyond their original intentions (Suddaby, 2010; Molloy \& Ployhart, 2012). These re-elaborations can be understood as happening within an evolutionary process in which concepts go through successive stages of emerging excitement, followed by validity challenges (linked to tidying up typologies), and either transformation or decline. This re-elaboration life-cycle model is set in motion by an ongoing scholarly dynamic between, on the one hand, broad problem-framing approaches that aim to keep concepts relevant and connected with the larger, albeit messier, world; and, on the other hand, narrower problem-framing approaches that call for rigor, validity, and conceptual clarity. The dialectic between these two approaches helps advance knowledge (Hirsch \& Levin, 1999).
} 
ambiguity and divergence in the definitions and conceptual domains of each stand-alone categorisation threaten the conceptual clarity of the connections between them (ambiguity and divergence within categorisations). A second source may arise across categorisations. Ambiguity will appear if the connection is not based on a precise and parsimonious distinction between the concepts provided by one categorisation and those provided by the other. Divergence will arise if the conceptual domains of the categories to be connected have little common basis or are misaligned (e.g. one categorisation describes top management behaviours, whereas the other describes behaviours at the shop-floor level). Finally, a third source of poor conceptual clarity may be the form of connection. Thus, in the case of the connection between $\mathrm{C} / \mathrm{E}$ and $\mathrm{D} / \mathrm{I}$, researchers can take alternative approaches. For instance, constructs from one categorisation of controls can be incorporated into higher-order constructs provided by the other categorisation, or constructs from both categorisations can instead be integrated into new higher-order constructs; or, alternatively, the focus may be put on the joint effects of constructs from the various categorisations. Conceptual ambiguity is introduced if the form of connection is left underspecified. Divergence appears if the specific form in which the connection is conceptually put forward presents discrepancies from the cumulative knowledge about each categorisation, or from prior formulations of the form of connection. The relevance of the sources of conceptual ambiguity and divergence is likely to vary depending on the form of connection specified. We will thus consider the differential relevance of these three sources of ambiguity and divergence under each form of connection in our review and assessment.

\section{Review criteria}

\subsection{Selection and classification of studies}

We extensively searched the literature for published studies on $\mathrm{C} / \mathrm{E}$ and $\mathrm{D} / \mathrm{I}$ management controls. To use reliable high-quality sources, we selected 20 major accounting journals with three and four star-ratings in the 2012 Association of Business Schools Journal Quality Guide, plus five major general management scholar-oriented journals included in the 2012 Financial Times 45 journals list. ${ }^{5}$ We included top management scholar-oriented journals because one of our key

\footnotetext{
${ }^{5}$ The list of 20 accounting journals is: Abacus, Accounting and Business Research, Accounting Auditing and Accountability Journal, Accounting Forum, Accounting Horizons, Accounting Organizations and Society, Behavioral Research in Accounting, British Accounting Review, Contemporary Accounting Research, Critical Perspectives on Accounting, European Accounting Review, International Journal of Accounting, Journal of Accounting and Economics, Journal of Accounting Literature, Journal of Accounting Research, Journal of Accounting Research Auditing and Finance, Journal of Management Accounting Research, Management Accounting Research, Review of Accounting Studies and The Accounting Review. The 5 top non-accounting
} 
references, A\&B96, was published in a leading management journal and we were interested in tracing any later publication on $\mathrm{C} / \mathrm{E}$ controls in these publications. Our search timeframe was 1995-2015 since 1995 is the publication year of the oldest of our key references on either C/E or D/I (Simons, 1995). We searched within each journal for C/E studies that referenced A\&B96 or Ahrens and Chapman (2004) ${ }^{6}$ and whose full text contained all three search terms 'coercive' and 'enabling' and 'management control'. We did not specify additional search words as required criteria for inclusion because we wanted to keep our initial search as comprehensive as possible within the scope of our research goals. After a preliminary trial search, we chose not to include 'control' as an alternative single word in our search string in order to screen out studies focused on engineering or physical controls that were not relevant for our research goals. This first stage identified 50 potential hits for $\mathrm{C} / \mathrm{E}$ controls. Likewise, we searched within each journal for D/I studies that referenced Simons (1995; 2000 or 2013) and whose full text held all three search words 'diagnostic' and 'interactive' and 'management control'. This gave us 107 potential hits for $\mathrm{D} / \mathrm{I}$ controls. We searched separately for $\mathrm{C} / \mathrm{E}$ and $\mathrm{D} / \mathrm{I}$ controls because we sought to identify studies on management controls that relied on at least one of the two stand-alone categorisations. Combining the total 157 hits from the two lists, we detected 23 duplicate papers that appeared in both lists and thus we were left with a list of 134 unique papers. We double-checked our initial selection procedure by performing a Google Scholar search of studies available in English using the same search string and inclusion criteria and we identified the same 134 studies.

We then performed a preliminary content analysis of these articles to remove those that were not relevant to our study. For our aim, relevant studies are studies that use the $\mathrm{C} / \mathrm{E}$ and/or the $\mathrm{D} / \mathrm{I}$ categorisation to investigate management controls. Therefore, even if the full text of an article contained references to $\mathrm{C} / \mathrm{E}$ or $\mathrm{D} / \mathrm{I}$ as well as to management control, we considered it not relevant if it met at least one of the two following criteria. First, an article was removed if the terms 'coercive', 'enabling' 'diagnostic' or 'interactive' were present in the text but are not applied to the analysis of MCSs. For example, Speklé and Verbeteen (2014) mention 'diagnostic' and 'interactive' but their analysis of how contractibility moderates the effects of an MCS on the performance of public sector categorisations is based on an alternative taxonomy that distinguishes between operational, incentive-oriented, and exploratory uses of MCSs. Second, an article was

included journals are Academy of Management Journal, Academy of Management Review, Administrative Sciences Quarterly, Journal of Management Studies and Strategic Management Journal. The combined use of these journals' lists has its precedents in accounting research (e.g. Elshandidy et al., 2018).

${ }^{6}$ We included the reference to Ahrens and Chapman (2004), as it was the first article in MCS literature to apply the A\&B96 framework. Therefore, subsequent published articles on C/E controls could cite this article instead of A\&B96. 
also excluded if, despite mentioning MCSs, these are not its object of analysis. For instance, Dowling and Leech (2014) allude to MCSs but they rely on coercive and enabling types of formalisation to examine audit support systems as processes for controlling audit quality. One of the authors examined the $\mathrm{C} / \mathrm{E}$ hits and another one examined the $\mathrm{D} / \mathrm{I}$ hits excluding duplicates. Based on the pre-defined eligibility criteria above, the two researchers classified each of the allotted papers as relevant, clearly irrelevant, or doubtful. In the cases labelled as doubtful in the first round (20 articles, or 15\%), the third author provided a second opinion that, if positive, determined classification. If the second opinion also indicated doubts ( 6 articles, so less than 5\%), the three researchers convened to discuss the specific case until consensus was reached. Following this procedure, 75 papers were considered to fulfil at least one of the criteria for exclusion and were consequently removed. This sequence left us with 59 relevant studies on MCS that rely on either $\mathrm{C} / \mathrm{E}, \mathrm{D} / \mathrm{I}$, or both (see Figure 1).

Subsequently, we agreed on the criteria for assessing the degree of reliance of the identified studies on either $\mathrm{D} / \mathrm{I}$ or $\mathrm{C} / \mathrm{E}$ or both (see next paragraph for details on the classification procedure). Each of the three authors independently engaged in a content analysis of each of the 59 relevant studies, classifying each study into one of five groups depending on the degree of reliance on each categorisation. We then compared each of three resulting classifications and found a high degree of consistency. Disagreements were resolved by consensus among the three authors. This procedure led us to draw up the classification shown in Figure 1.

\section{INSERT FIGURE 1 ABOUT HERE}

As reported in Figure 1, studies that neither explicitly nor implicitly conceptualise a connection between elements of $\mathrm{C} / \mathrm{E}$ and $\mathrm{D} / \mathrm{I}$ were classified into Groups 1 or 2 . Group 1 refers to papers that draw on the $\mathrm{C} / \mathrm{E}$ distinction, but not on $\mathrm{D} / \mathrm{I}$. Group 2 refers to papers that draw on $\mathrm{D} / \mathrm{I}$, but not on $\mathrm{C} / \mathrm{E}$. The third group includes papers that explicitly draw on both distinctions because they explicitly conceptualise a connection between elements of C/E and D/I. Papers in Group 4 mainly draw on $\mathrm{C} / \mathrm{E}$ and are in the perimeter of the $\mathrm{D} / \mathrm{I}$ categories. They do not explicitly draw on the $\mathrm{D} / \mathrm{I}$ categorisation, but are informed by it, given that they extend the properties of coercive and enabling systems to include some properties of the D/I categories. For example, some papers in Group 4 define an enabling use of MCSs in terms of debate and dialogue on strategic uncertainties (Hartmann \& Maas, 2011: 445); ongoing interactions between managerial actors (Jordan \& Messner, 2012); and frequency in the use of information (Mahama \& Cheng, 2013). Papers in 
Group 5 primarily draw on the D/I distinction and are in the perimeter of the C/E categories. These papers extend the properties of diagnostic and interactive systems (Simons, 1995, 2000) to include properties of coercive or enabling systems. Bruining, Bonnet and Wright (2004), for instance, describe interactive control in terms of the categorisation in self-managing teams, and Tuomela (2005) does so in terms of the enhanced visibility of actions.

\subsection{Criteria for assessing conceptual clarity}

Once we had obtained Figure 1, each of the three authors independently engaged in a subsequent in-depth analysis of the content of the 59 relevant studies to detect those aspects that may threaten conceptual clarity in this stream of literature. The purpose of this second analysis was to identify specific points of conceptual ambiguity or divergence in studies on the $\mathrm{C} / \mathrm{E}$ and $\mathrm{D} / \mathrm{I}$ categorisations. We could not find any prior study that had empirically investigated conceptual clarity and that had analysed these aspects, hence we agreed to proceed inductively. To this aim we initially listed multiple aspects to judge as potential drivers of ambiguity and divergence and these included: object of analysis; theoretical framework; level of analysis; research method; construct definition; inherent properties; implications and outcomes of the constructs; sensemaking perspective; and design driven vs. style-of-use driven choice. We separately codified each of the 59 articles according to these aspects. We met and discussed our preliminary findings. As we collated our findings, we observed that some of the aspects that differed across the 59 articles were unsurprisingly related to distinct research goals (e.g. objects of analysis, underlying theoretical frameworks, levels of analysis, research methods) and to operationalisation aspects (e.g. individual features versus overall constructs, dichotomy, and consequent one-scale measurement versus duality and two-scale measurement). We agreed that since the focus of the current study is on conceptual clarity, we centred our attention only on those aspects bearing on conceptualisation and definitional issues. We then had a face-to-face discussion of our codified findings on those aspects. We concluded that there were three points that emerged as sources of conceptual ambiguity and divergence in the literature presented in Figure 1. We then introduced these three points, which are discussed in further detail in the forthcoming sections as they are used to organise our findings. The three points are: (1) the perspective from which the various studies undertake the analysis; (2) whether the studies consider the categorisations are a result of a design-driven choice, or a result of a style-of-use choice; and (3) the properties defining the construct of the categorisations. 
The first point of conceptual ambiguity and divergence, i.e. perspective, includes two related aspects: organisational position and decision focus. Organisational position refers to the decision of the researcher to study a phenomenon or situation from the point of view of specific actors in the organisation. It establishes which actors the researcher is mainly interested in and from whose point of view a phenomenon or situation is understood. For example, MCSs can be studied from the standpoint of top management (for instance, how top managers set direction and objectives and monitor whether targets have been met) or from the standpoint of lower- and middle-level managers and employees (for example, how MCSs give them support in assessing progress and in decision-making) (Wouters \& Wilderom, 2008). Decision focus refers to the extent to which the decisions affected by MCSs under analysis primarily have strategic contents (e.g. selection of product-markets and positioning) or operational contents (for instance, day-to-day activities, tasks, and work processes).

The second point of conceptual ambiguity and divergence refers to whether categories of controls are considered the result of a design choice, or are considered to derive from a style-ofuse choice. ${ }^{7}$ The differentiation between design and use attributes of MCSs is generally considered meaningful for research purposes (Cugueró-Escofet \& Rosanas, 2013; Ferreira \& Otley, 2009; Hall, 2010). Design attributes refer to the technical features of MCSs, such as the presence of a given technique or practice, the selection and definition of metrics and procedures, and the characteristics of the content and display format of the information provided by the system; as well as the degrees of sophistication, completeness, detail, accuracy, and accepted margin of tolerance in the designed practices (e.g. Cardinales, 2008, Chenhall, 2007; Chenhall \& LangfieldSmith, 1998; Chenhall \& Morris, 1986; Fisher, 1995; Gerdin, 2005). In turn, the use attributes of MCSs may refer to: (1) intensity of use - that is, the extent to which users draw on the system to support their work (Dekker, Groot \& Schoute, 2012; Mahama \& Cheng, 2013); and (2) style-ofuse - the way these MCSs are actually used, as expressed by the patterns of attention of the different actors and the nature of the communication processes surrounding the MCS (e.g. Abernethy \& Brownell, 1999; Ferreira \& Otley, 2009; Hopwood, 1972, 1973; Hall, 2010). Design and use aspects are conceptually different. Even if an MCS can be designed with an intended purpose in mind, a given design potentially leaves room for varying intensities of use and different styles-of-use. Therefore, use attributes of MCSs are not necessarily determined by design (e.g. a

\footnotetext{
${ }^{7}$ We also identify a stream of literature that has focused on the development process by which control systems are designed and implemented (e.g. De Haas \& Kleingeld, 1999; Fried, 2010; Groen, Wouters \& Wilderom, 2012; Wouters \& Rojimans, 2011; Wouters \& Wilderom, 2008). In this paper, we focus on the characteristics of control systems themselves, and not their development process, and therefore we only conduct a limited analysis of studies in this stream.
} 
balanced scorecard designed in a certain way, with the intention to be used diagnostically to monitor certain outcomes, may be used or not, and may be used as intended, on an exception basis, or not used).

Finally, the third point of conceptual ambiguity and divergence we identified covers the properties of controls. These properties refer to the inherent features of control practices, be they design-based (e.g. the inclusion of financial and/or non-financial metrics) or use-based (e.g. use on an exception basis). Properties are different from their implications and outcomes. Implications of controls are the effects that they have on the activities of managers and organisational processes (such as effective management of attention and facilitation of learning). These implications are eventually reflected in terms of outcomes (such as business unit performance) (Marginson, 2002). Because distinct concepts (e.g. participation and autonomy) defined by different sets of properties may share identical implications (such as empowerment) and identical outcomes (e.g. improved individual performance), we think it is interesting to examine properties (rather than implications or outcomes) as a third relevant source of conceptual ambiguity and divergence.

We next examine the depth of ambiguity and divergence in the literature on $\mathrm{C} / \mathrm{E}$ and $\mathrm{D} / \mathrm{I}$ for each of these three points. In Section 4, we discuss whether and how these three points manifest within and across categorisations. In Section 5 we analyse the different forms of connections between $\mathrm{C} / \mathrm{E}$ and $\mathrm{D} / \mathrm{I}$ that have been proposed in the literature and assess how far these points of ambiguity and divergence are problematic for each form of connection.

\section{Assessment of conceptual clarity within and across categorisations}

In Section 4.1, we examine how far the three identified points of conceptual ambiguity and divergence are present in the literature on C/E (i.e. Group 1 in Figure 1). In 4.2 we replicate the analysis for the literature on D/I (i.e. Group 2 in Figure 1). After separately assessing whether conceptual clarity is threatened by ambiguity and divergence within categorisations in the selected literature, in 4.3 we compare the literature on the two stand-alone categorisations to see whether there is ambiguity and divergence across categorisations.

\subsection{Assessment of conceptual clarity in studies on $C / E$ controls}


Studies in Group 1 in Figure 1 generally draw from Adler and Borys (1996) (A\&B96) and Ahrens and Chapman (2004) to define C/E controls. For A\&B96, organisations can rely on bureaucratic formalisation to pursue the production of fool proof systems, to constrain employee behaviour, and coerce effort and reluctant compliance from employees (i.e. coercive formalisation) or, alternatively, to help employees to master their tasks and enable them to deal directly with the contingencies of their work (i.e. enabling formalisation). The distinction between coercive and enabling formalisation relies on four underlying principles, namely: repair, internal transparency; global transparency; and flexibility. Following Ahrens and Chapman (2004)'s first application of A\&B96 to MCSs, other studies in Group 1 (e.g. Jorgensen \& Messner, 2009; Neu et al. 2014) have stressed that the four features underlying the distinction between $\mathrm{C} / \mathrm{E}$ controls collectively shape the degree of autonomy of the organisational members in carrying out their jobs.

In line with $\mathrm{A} \& \mathrm{~B} 96$, the literature on $\mathrm{C} / \mathrm{E}$ controls has tended to adopt the perspective of lower- and middle-level managers and employees. The vast majority of these studies examine the extent to which those in lower and middle organisational positions experience the systems as supporting them and whether they draw on the systems to master their work or feel coerced by them. What makes the system coercive or enabling is how it is experienced by staff in lower and middle ranks, even though this outcome may be the result of top management choices regarding the system features. An emerging stream of qualitative studies has included the perspective of top management positions in addition to those of the lower ranks (e.g. Ahrens \& Chapman, 2004; Jorgensen \& Messner, 2009) to examine the dynamic interaction between the intentions of top managers and the perceptions of lower and middle-level managers.

As far as decision focus is concerned, the distinction between coercive and enabling systems as originally formulated describes various ways of formalising individual tasks (A\&B96) and relationships between tasks (Adler, Goldoftas \& Levine, 1999). Along these lines, some studies have drawn on the $\mathrm{C} / \mathrm{E}$ distinction to examine, for instance, how MCSs structure day-today operational management (Ahrens \& Chapman, 2004) and shape task performance (Englund \& Gerdin, 2015). Overall, the literature on $\mathrm{C} / \mathrm{E}$ shows little conceptual ambiguity and high convergence in this regard as it mainly focuses on operational decisions. Yet, building on this operational focus, and in addition to it, some studies have further reflected on how operational actions are instrumental in implementing strategy and on how new strategies may emerge from innovative operational actions (e.g. Ahrens \& Chapman, 2004).

With regard to the conceptualisation of $\mathrm{C} / \mathrm{E}$ controls as design-driven choice or as choice driven by style-of-use, A\&B96's four underlying principles describe logic of procedure design 
and reflect the design features of a system. Hence, according to A\&B96, the $\mathrm{C} / \mathrm{E}$ distinction is design focused (A\&B96:81) and whether a system is enabling or coercive is a design-driven choice. The consideration of $\mathrm{C} / \mathrm{E}$ as a design-driven choice is well established in the studies in Group 1 (e.g. Ahrens \& Chapman, 2004; Cools, Emmanuel \& Jorissen, 2008; Jorgensen \& Messner, 2009). Finally, and as far as properties are concerned, papers in Group 1 have tended to directly draw on the four design properties proposed in the original formulation by A\&B96 (e.g. Ahrens \& Chapman, 2004; Cools et al., 2008; Jorgensen \& Messner, 2009).

Overall, the literature on C/E (i.e. studies in Group 1 in Figure 1) shows little conceptual ambiguity and considerable conceptual convergence. There is a high degree of consensus in adopting the perspective of lower management and employees and focusing on operational decisions. The initial formulation by A\&B96 suggests a choice driven by design. This is in general the position adopted by later research on $\mathrm{C} / \mathrm{E}$ controls, even if some subsequent lines of processview qualitative research have pointed to styles-of-use considerations. Finally, most of the literature on enabling and coercive MCSs converges on the properties proposed by A\&B96.

\subsection{Assessment of conceptual clarity in studies on D/I controls}

Studies in Group 2 in Figure 1 draw on Simons $(1995,2000)$ to distinguish between diagnostic and interactive control systems $(\mathrm{D} / \mathrm{I})$, depending on the way that managers use the information provided by feedback and measurement systems. Diagnostic control systems are MCSs used by managers on an exception basis to monitor achievement of pre-established standards, detect deviations, and trigger corrective actions (Henri, 2006; Simons, 1995; 2000; Widener, 2007). Interactive control systems are MCSs used by managers on a frequent and regular basis to involve themselves personally in the decision activities of subordinates, signal the desirability of focusing on strategic uncertainties, and hence foster the emergence of new initiatives and strategies (Simons, 2000). A number of papers have analysed how firms manage aspects of organisational life drawing on the D/I distinction (e.g. Abernethy \& Brownell, 1999; Bisbe \& Otley, 2004) as well as on the interplay between diagnostic and interactive controls (e.g. Bedford, 2015; Henri, 2006; Marginson, McAulay, Roush \& van Zijl, 2014; Widener, 2007).

According to Simons (1995:6), the D/I distinction examines control from the perspective of top management positions, and it is less concerned with how lower level managers use control systems for operational activities. Most studies drawing on $\mathrm{D} / \mathrm{I}$ adopt this top management perspective (e.g. Henri, 2006; Naranjo-Gil \& Hartmann, 2007; Widener, 2007). Departing from this mainstream, some studies have found D/I informative and meaningfully applicable to lower 
hierarchical levels (e.g. Frow, Marginson \& Ogden, 2010; Osborn, 1998; Su et al., 2015). These less frequent studies share two commonalities. First, their sense-making perspective is based on the position of organisational actors who - even if they are not top executives - are sufficiently highly ranked to take decisions with strategic content. Second, the organisational actors whose perspective is taken have the prerogative to make deliberate choices about the communication patterns with subordinates and the intensity of use of controls. With regard to decision focus, Simons $(1995,2000)$ centres on strategic decisions and seeks to grasp how organisations form, implement, and control strategies (e.g. Simons, 1995: 9-10; 20-1). Accordingly, the vast majority of studies in Group 2 stress a strategic decision focus (e.g. Abernethy \& Brownell, 1999; Arjalies $\&$ Mundy, 2013). Overall, this literature shows high convergence in adopting top management perspective and focusing on strategic contents.

With regard to the conceptualisation of $\mathrm{D} / \mathrm{I}$ controls as design driven choice or choice driven by style-of-use, according to Simons, D/I are characterised by specific communication processes and attention patterns. For instance, interactive controls require regular, frequent personal attention from managers whereas diagnostic control systems require attention only when there is variance. Interactive controls require face-to-face meetings in a challenging and dialogic mode, whereas interaction with the system may suffice for diagnostic systems. In principle, any MCS with given design characteristics can potentially become a diagnostic or an interactive system, depending on the patterns of attention and communication processes associated with it. Consequently, D/I epitomise styles-of-use of MCSs and the distinction between diagnostic and interactive controls does not refer to design features. In accordance with Simons' original formulation, the vast majority of papers in our literature search characterise D/I as styles-of-use (e.g. Abernethy \& Brownell, 1999; Bedford, 2015; Bisbe \& Otley, 2004; Henri, 2006; Kober, Ng \& Paul, 2007; Mikes, 2009; Naranjo-Gil \& Hartmann, 2007; Widener, 2007).

As far as the properties of D/I controls are concerned, Simons' $(1995,2000)$ formulation provides generic nominal definitions of both styles-of-use, and indicates that these styles-of-use are composites of attributes related to intensity of use, communication patterns, and focus of organisational attention. Yet, Simons $(1995,2000)$ does not give a single clear-cut enumeration of the properties defining $\mathrm{D} / \mathrm{I}$. The absence of such a single clear-cut enumeration opens the door to ambiguity and divergence regarding properties in studies in Group 2. Even though all the studies in this group directly adopt Simons' $(1995,2000)$ formulation of D/I and show considerable agreement in their generic nominal definitions, the operational definitions of both styles-of-use show a considerable degree of variety across studies. Hence, we often find that some of the properties enumerated by Simons $(1995,2000)$ are contemplated in the operational definitions of 
some studies, but not in others (e.g. non-inclusion of focus on strategic uncertainties in the definition of interactive systems in Abernethy \& Brownell (1999), Bisbe \& Otley (2004) or Su et al.(2015); non-inclusion of use on an exception basis in the definition of diagnostic systems in Widener (2007)). Partial adoptions of the original attributes introduce ambiguity as the conceptual domains of the original constructs are not fully captured (Molloy \& Ployhart, 2012; Podsakoff et al., 2016; Suddaby, 2010). Moreover, the diversity of partial adoptions introduces conceptual divergence in the operational definitions of styles-of-use across studies. ${ }^{8}$ The ambiguity and divergence introduced in the various operational definitions pose potential threats to the construct clarity of D/I (Molloy \& Ployhart, 2012) and could harm the comparability of findings from different studies.

Overall, the literature on D/I (i.e. studies in Group 2) generally agrees in taking the perspective of top management positions and in mainly focusing on strategic decisions. Almost all studies coincide with Simons (1995) in that D/I is concerned with styles-of-use. However, despite general agreement on the nominal definitions, there is wide variation in the operational definition of the properties of diagnostic and interactive controls.

\subsection{Categorisations compared: assessment of conceptual clarity across categorisations}

Our analysis in 4.1. and 4.2. shows little conceptual ambiguity and considerable conceptual convergence within the studies that draw on each stand-alone categorisation. However, little ambiguity and considerable convergence within each categorisation does not preclude the presence of conceptual ambiguity or conceptual divergence across categorisations. Researchers interested in establishing conceptual connections between $\mathrm{C} / \mathrm{E}$ and $\mathrm{D} / \mathrm{I}$ must be aware of potential conceptual ambiguity and divergence across the two categorisations because these could threaten clarity in the conceptualisation of the connection. Both $\mathrm{C} / \mathrm{E}$ and $\mathrm{D} / \mathrm{I}$ examine the engagement between top management and lower ranks. However, our analysis reveals that the perspective from which the analysis is undertaken varies across categorisations. $\mathrm{C} / \mathrm{E}$ generally takes the perspective of positions in the lower ranks, whereas D/I generally takes the perspective of top management positions. Conceptual ambiguity is likely to arise if studies drawing on both $\mathrm{C} / \mathrm{E}$ and $\mathrm{D} / \mathrm{I}$ fall short of explaining how the perspectives from which the two categorisations undertake the analysis are made compatible. Studies may visualise the categorisations from the perspective of top management or from that of the lower ranks, or may adopt both at the same time. However, each

\footnotetext{
${ }^{8}$ Another source of conceptual divergence may be the inclusion of additional properties not originally included in Simons (1995, 2000) (see Section 5.2.3).
} 
of these options poses theoretical challenges, as a meaningful connection requires re-elaboration of the stand-alone categorisations to ensure that perspectives dovetail or at least have some common basis. On the same grounds, divergence, and ambiguity may arise in relation to the compatibility between the operational decision focus of $\mathrm{C} / \mathrm{E}$ and the strategic decision focus of $\mathrm{D} / \mathrm{I}$.

Another potential source of conceptual ambiguity and divergence in the connection is whether categorisations are design-driven or driven by styles-of-use. If, for instance, D/I is taken to be driven by styles-of-use and $\mathrm{C} / \mathrm{E}$ as design-driven (as suggested by the original formulation of the categorisations), researchers must explain how these can be meaningfully combined to portray distinct angles of a management control situation. In this case, the question is how $\mathrm{C} / \mathrm{E}$ and $\mathrm{D} / \mathrm{I}$ relate and can jointly provide additional insights on the workings of control. If both categorisations are instead considered to capture styles-of-use attributes, one must still answer the same question as to how they relate to one another. Furthermore, in such case, one needs to reelaborate the initially design-driven $\mathrm{C} / \mathrm{E}$ categorisation. To maintain conceptual clarity, it should be clear what C/E styles-of-use encompass, and how these differ from D/I styles-of-use.

Regarding the properties of $\mathrm{C} / \mathrm{E}$ and $\mathrm{D} / \mathrm{I}$, maintaining clarity in conceptualising the connection between them requires both that: (a) properties of the categories of one categorisation be clearly differentiated from the properties of the other; and (b) the conceptual domains of the categories to be connected match the conceptual domains as defined in the relevant literature. Under an evolutionary, dynamic view of conceptualisation (Hirsch \& Levin, 1999), definitions of constructs may justifiably depart from their original domains, but this drift should be justified in light of new empirical contexts or new theoretical insights. Redefined properties should be explicitly stated and distinguished from properties of other conceptually related constructs. In the absence of such explanations, ambiguity is introduced, and clarity is undermined in the conceptualisation of the connection (Molloy \& Ployhart, 2012; Podsakoff et al., 2016; Suddaby, 2010). Hence, the challenge for studies seeking to connect $\mathrm{C} / \mathrm{E}$ and $\mathrm{D} / \mathrm{I}$ is to deal with the conceptual ambiguity and divergence across categorisations, while preserving conceptual convergence with prior literature on each categorisation.

Our analysis indicates that conceptual clarity concerns are likely to arise when connecting $\mathrm{C} / \mathrm{E}$ and $\mathrm{D} / \mathrm{I}$ because of ambiguity and divergence across categorisations. Yet, the extent to which these potential threats to conceptual clarity materialise depends on which form of connection is specified. Hence, we now turn to the identification of the forms of connection that have been proposed in the literature. This will allow us to examine how the points of conceptual ambiguity 
and divergence across categorisations manifest themselves under different forms of connection and consequently, let us assess the conceptual clarity of each of these forms.

\section{Forms of connection between $C / E$ and $D / I$ and assessment of their conceptual clarity}

\subsection{Forms of connection between $C / E$ and $D / I$}

In this section, we undertake a systematic review of the 23 papers listed under Groups 3, 4, and 5 in Figure 1 to investigate how the connection between categorisations has been conceptualised in the literature. As a result of this review, we inductively identify several alternative approaches that entail five different forms of connection with different implicit research models (see Table 1). The identification of this variety evidences divergence in the conceptualisation of the form of connection between categorisations. ${ }^{9}$

INSERT TABLE 1 ABOUT HERE

Under approach 1, one categorisation is used to examine a given aspect (e.g. an issue or implication at a certain organisational level or in a certain area of activity) of a broader control situation, whereas the other categorisation informs the analysis of another aspect of that situation. Even if $\mathrm{C} / \mathrm{E}$ and $\mathrm{D} / \mathrm{I}$ are not strictly combined, one single study can separately draw on both categorisations to tackle different aspects of a broader control situation.

Alternatively, researchers can draw on both $\mathrm{C} / \mathrm{E}$ and $\mathrm{D} / \mathrm{I}$ to jointly shed light on one given aspect of a control situation. One way of doing so involves adopting inclusion approaches whereby categories are redefined such that a higher-order categorisation includes categories of another

\footnotetext{
${ }^{9}$ None of the studies under review adopts a causal relationship approach in which categories from one categorisation are antecedents or effects of categories in the other categorisation. In some studies, the terms 'enabling' and 'interactive' (and, less often, 'coercive' and 'diagnostic') are indistinctly used within one study, without any reported difference in meaning between the two terms (e.g. Fried, 2010). On other occasions, categories in one categorisation have been operationally defined on the basis of properties that are generally acknowledged to correspond to the other categorisation (e.g. 'an enabling use [of a system] means [the system] foster[s] debate and dialogue on strategic uncertainties,' or '[enabling systems] require attention from all managers on a day-to-day basis'). In these cases, as some properties of enabling systems coincide with those of interactive systems and there is no further indication of any property on which the categories 'enabling' and 'interactive' would depart from each other, the differences between the properties of 'enabling' and 'interactive' systems are blurred. As evidenced by the discussion in Section 4, categories in $\mathrm{C} / \mathrm{E}$ should not be treated as interchangeable with D/I. Interchangeability of the two categorisations injects unwarranted extraneous meaning into the definition of at least one of them, and therefore severely damages conceptual clarity.
} 
lower-order one. In approach 2, D/I categories are considered one of the constituent components of $\mathrm{C} / \mathrm{E}$ categories. For instance, a diagnostic use of MCSs is considered one of the constitutive dimensions of a coercive MCS. By contrast, in approach 3 the types of bureaucratic formalisation are considered one of the constituent components of D/I categories. For instance, enabling is considered one of the constituent dimensions of interactive controls.

Finally, researchers can combine both categorisations, allowing combinations of the coercive versus enabling distinction and the diagnostic versus interactive distinction to create new theoretical types of MCSs. Under approach 4, each new type represents a specific combination of design and style-of-use attributes. Under approach 5, each new type embodies a combination of two style-of-use attributes by which a new higher-order style-of-use is defined.

\subsection{Assessment of conceptual clarity and research models for each form of connection.}

We describe all approaches and illustrate their implicit research models in Figures 2 to $7 .{ }^{10}$ In this section, we also examine the conceptual clarity of the connections using the points of conceptual divergence and ambiguity that we have introduced in Section 2. In Table 2, the rows show the diverse approaches to the connection between categorisations, whereas the columns show the three identified points of conceptual ambiguity and divergence. The cells summarise whether and how these three points manifest themselves under each connection approach. Cells in grey indicate threats to conceptual clarity.

INSERT TABLE 2 ABOUT HERE

\subsubsection{Coexisting categorisations}

In studies adopting approach 1 (i.e. the coexistence approach), each categorisation is used to examine a separate part of a broader and complex control situation. Here, the two categorisations are not strictly combined to collectively portray a certain practice or implication from the perspective of one single position and with a given decision focus. Rather, each categorisation is used independently to undertake the analysis of separate issues or implications

\footnotetext{
${ }^{10}$ The arrows in these figures can be interpreted by quantitative researchers as measurement model links or causal relationships. From a qualitative standpoint, the arrows can also be interpreted as flows in a process or as indications that a certain theoretical lens is used to make sense of a phenomenon or situation.
} 
from the perspective of a different organisational actor's position, with a different decision focus or in different areas of the organisation (see Figure 2). For example, a given broad management control situation may be examined by drawing on the $\mathrm{C} / \mathrm{E}$ distinction to examine operational aspects from the perspective of lower-level managers, while at the same time drawing on D/I to examine strategic aspects from the senior management perspective. Some components within the broader control situation are examined through the $\mathrm{C} / \mathrm{E}$ distinction and others through the $\mathrm{D} / \mathrm{I}$ distinction, but no single component is simultaneously analysed through both.

Researchers who take a broader system or package approach to the study of MCSs (Bedford \& Malmi, 2015; Grabner \& Moers, 2013; Malmi \& Brown, 2008) may be interested in giving a rich picture of a complex management situation by simultaneously examining what is happening in an organisation from the perspectives of different organisational actors, regarding different decision foci or in different areas. Davila, Foster, and Li (2009a:327) provides an instance of this approach as it suggests that 'interactive systems ... allow top management to guide the search stage of the innovation process .... While interactive systems speak to the front end of the innovation process, the concept of enabling bureaucracy addresses the role of MCSs throughout the stages of assimilation'. Studies that take a dynamic process view of MCSs may also adopt a coexistence approach in examining how management control situations emerge as outcomes of the many ongoing interactions between organisational actors, including those between top management and operational management (Jordan \& Messner, 2012). ${ }^{11}$

\subsubsection{Conceptual clarity in the coexistence approach}

Given the different objects of analysis in approach 1, the fact that $\mathrm{C} / \mathrm{E}$ and $\mathrm{D} / \mathrm{I}$ do not share perspective is unproblematic, and conceptual divergence across categorisations does not threaten conceptual clarity either. In fact, as process-view studies draw on one of the categorisations to undertake the analysis from the perspective of certain organisational actors while at the same time drawing on the other categorisation from the perspective of other actors, they may highlight the dynamic intertwining across multiple organisational positions or multiple decision foci. Along the same lines, conceptual divergence across categorisations regarding whether they are driven by design or by style-of-use is not necessarily an issue for conceptual clarity under this approach. Thus, even if the distinction of 'enabling versus coercive' is driven by design, studies under

\footnotetext{
${ }^{11}$ Jordan and Messner (2012) illustrate how a change in top management control in favour of using specific indicator targets as the basis for evaluating middle manager performance endangers the enabling character of a control system. In a similar vein, papers that focus on the system development processes (e.g. Wouters \&Wilderom, 2008) have reported how enabling systems at the lower and middle levels may be disturbed by top-mandated initiatives that stress setting and meeting targets, as well as management by exception. Although neither of these two papers explicitly refers to D/I, their analysis hints at the possibility of conceptualising connections between $\mathrm{C} / \mathrm{E}$ and $\mathrm{D} / \mathrm{I}$ as coexisting categorisations.
} 
approach 1 may stress that enabling and coerciveness at certain organisational levels or in certain areas may engage with the influence of styles-of-use of MCSs at other organisational levels or in other areas (Jordan \& Messner, 2012). Lastly, the coexistence approach does not require any adaptation or re-elaboration of the conceptual domains of the categories as defined in the original formulation of $\mathrm{C} / \mathrm{E}$ and $\mathrm{D} / \mathrm{I}$, as those formulations can be adopted maintaining conceptual separation between the constructs. Even if conceptual clarity is not at stake, major challenges under approach 1 are both substantive (i.e. the understanding of the dynamics of the interaction between organisational positions or between decision-foci) and methodological (i.e. the collection of data on multiple angles from multiple sources).

\subsubsection{Research questions under the coexistence approach}

The coexistence approach is based on the idea that each of the two categorisations separately produces implications and/or separately sheds light on distinct issues (Figure 2). Studies connecting $\mathrm{C} / \mathrm{E}$ and $\mathrm{D} / \mathrm{I}$ under the coexistence approach acknowledge that the implications produced or the issues to be explored differ across categorisations. Consequently, research questions under the coexistence approach address multiple aspects of a broader control situation, taking advantage of the contributions of each categorisation. Figure 2 provides examples of generic research questions that can be tackled taking this approach. Given the multiple sources needed to capture this rich picture, longitudinal field studies appear to be particularly well-suited for addressing the challenges. As this approach stresses that these various implications or issues are parts of a broader control situation, research questions can also address how the dynamics between these separate implications shape organisational outcomes.

INSERT FIGURE 2 ABOUT HERE

\subsubsection{Inclusive categorisations}

Approaches 2 and 3 in Table 1 draw on both $\mathrm{C} / \mathrm{E}$ and D/I to jointly shed light on one given aspect of a control situation. To do so, studies under these inclusion approaches consider one of the categorisations as being of a higher-order and redefine its categories so that they include lowerorder categorisations.

\subsubsection{D/I as a dimension of $C / E$}


In approach 2, D/I categories are considered one of the constitutive dimensions of C/E. An example of this approach can be found in the pioneering quantitative study by Naranjo-Gil and Hartmann (2006). In line with A\&B96 and Ahrens and Chapman (2004), these authors initially build on the nominal definitions of coercive use (i.e. as an instrument to apply top-down control and boost centralisation) and enabling use of MCSs (i.e., as an instrument to foster self-control and to help employees deal with uncertainties and better master their functions). Exploring the development of operational definitions of coercive and enabling MCSs, Naranjo-Gil and Hartmann (2006) conceive of those as formative second-order constructs whose constituent traits include respectively diagnostic and interactive uses (Figure $3 a$ ). ${ }^{12}$ In a less explicit manner, Free's (2007) qualitative study also hints at interactive dialogue being a component of enabling systems and diagnostic controls being a component of coercive ones. ${ }^{13}$

\section{INSERT FIGURES 3 a AND $3 b$ ABOUT HERE}

\subsubsection{C/E as a dimension of $D / I$}

Under approach 3, the $\mathrm{C} / \mathrm{E}$ categories are conceptualised as one of the constitutive dimensions of D/I. Even if this approach has not been explicitly advocated in the papers included in this review, it can be logically inferred from some of them. Thus, Bisbe, Batista-Foguet, and Chenhall (2007) propose refining the conceptual domain of interactive controls to include noninvasive, facilitating, and inspirational involvement by top managers as an additional constitutive dimension. Tessier and Otley (2012:177) suggest that this form of involvement is an expression of an enabling system. If these two premises are accepted, enabling becomes one of the constitutive dimensions of the redefined construct of interactive controls (Figure $3 b$ ). In Bisbe et al. (2007), the argument for the refinement of Simons' baseline properties is that while baseline properties of interactive controls apply to the two quadrants in the bottom row of Figure $3 \mathrm{~b}$, their implications and outcomes as described by Simons (1995) (e.g. learning, innovation, and emergence of strategies) are restricted to the lower right quadrant (e.g. Bonner, Ruekert \& Walker, 2002). The suggested reformulation proposes that an MCS is interactive only if, in addition to

\footnotetext{
${ }^{12}$ Due to the miscellaneous nature of the dimensions in the composites (i.e. styles-of-use, information contents, and purpose) and the treatment of both the enabling/coercive distinction and the diagnostic/interactive distinction as dualities, the feasibility and precise meanings of the top right and bottom left quadrants in Figure $3 a$ are hard to interpret.

${ }^{13}$ The operationalisation of enabling systems by Chapman \& Kihn (2009) might also be interpreted as indicating partial support for interactive use being a dimension of enabling systems. Nevertheless, Chapman \& Kihn (2009) do not theoretically or empirically develop the relationships between enabling and interactive control systems as these relationships are not central to their paper.
} 
being an object of permanent attention by top and middle management, being used in face-to-face communication, and focusing on strategic uncertainties (e.g. the baseline properties in the lower row of Figure $3 b$ ), it is also non-invasive (i.e. enabling). Under this approach, MCSs that are objects of permanent attention and focus on strategic uncertainties, but are invasive (e.g. coercive), will be unlikely to foster learning, innovation, and emergence of strategies (e.g. Bonner et al., 2002; Jordan \& Messner, 2012), and thus would not be considered interactive controls.

\subsubsection{Conceptual clarity in the inclusion approaches}

The inclusion approaches pose threats to conceptual clarity that stem from the divergence across categorisations (see Table 2). As presented in Section 4, C/E tends to take the perspective of lower management and employees and to refer to operational decisions, whereas D/I takes the perspective of top management positions and has a strategic decision focus. If the categories of one categorisation scheme are treated as constitutive dimensions of the other scheme, conceptual clarity may be threatened if the two categorisations adopt different organisational position points of view or do not share a common decision focus. Thus, for categories to be considered sound constitutive dimensions of other categories of controls, some conceptual adaptation of at least one of the categorisations is required. Whether $\mathrm{C} / \mathrm{E}$ and $\mathrm{D} / \mathrm{I}$ can accommodate the perspective of one common organisational position from which the analysis is undertaken, and a common decision focus is not obvious and cannot be taken for granted. Hence, studies under the inclusion approaches need to explain and justify how they visualise both categorisations from the perspective of top management or from that of the lower ranks. That is, how are interactive controls translated to the perspective of middle and lower levels of management? Alternatively, how can enabling systems be translated to the perspective of top management? Similarly, it is relevant for studies adopting inclusion approaches to theorise and disclose how they address the match between the operational decision focus of $\mathrm{C} / \mathrm{E}$ and the strategic decision focus of $\mathrm{D} / \mathrm{I}$. The extent to which the concept of interactive controls can be meaningfully extended to gain insights on operational decisions is open to debate. Along the same lines, it is still unclear in the literature whether enabling is an informative concept for examining strategic decisions at the top management level. Further theorising is needed to examine whether these conceptual leaps are feasible and wise. In that regard, for example, Naranjo-Gil and Hartmann (2006) consistently draw on both categorisations to focus on the analysis of strategy implementation. They highlight how in as much as operational actions are instrumental in implementing strategy and new strategies may emerge from innovative operational actions - this is an area in which operational and strategic decisions are intertwined. 
Conceptualising $\mathrm{D} / \mathrm{I}$ as a constitutive component of $\mathrm{C} / \mathrm{E}$ (or vice versa) further requires consistency in the driver of choice. For example, regarding approach 2, if the enabling versus coercive distinction is considered a design-driven choice, its constituent dimensions should be based on design-driven choices as well. However, the literature converges in considering that D/I is driven by styles-of-use. Conceptually re-elaborating $\mathrm{C} / \mathrm{E}$ to consider it as driven by styles-ofuse (or re-elaborating $\mathrm{D} / \mathrm{I}$ to consider it as design driven) would lead to divergence from the original formulations of $\mathrm{C} / \mathrm{E}$ and/or $\mathrm{D} / \mathrm{I}$. Researchers should ponder whether new empirical contexts or new theoretical insights justify introducing this divergence. Alternatively, enabling and coercive systems can be conceptualised as a mixture of dimensions, some driven by styles-ofuse, some not. For example, in Naranjo-Gil and Hartmann (2006), the miscellaneous dimensions that define enabling and coercive uses as second-order formative constructs include purpose, styles-of-use (i.e. diagnostic versus interactive), and type of information contents. The challenge in this case is to understand the actual substantive meaning of the resulting composite construct. Analogous concerns regarding the consistency in the drivers of choice (e.g. design versus stylesof-use) apply to approach 3.

This leads to the third point of conceptual ambiguity and divergence: the definition of the properties of the concepts of interest. To maintain conceptual clarity, the properties of the categories that inform the connection between categorisations are generally expected to match the properties of those concepts as defined in the previous literature on the stand-alone categorisations. However, striving for conceptual convergence across categorisations may again put convergence with prior literature in each categorisation at risk. Hence, the composite approach adopted in Naranjo-Gil and Hartmann (2006) includes D/I categories within the definition of C/E, but involves a departure from the original formulation in A\&B96 (as references to their design properties are absent). Consequently, the approach casts doubt on whether the conceptual domains of the coercive and enabling overarching constructs that result from the connection between categorisations are actually consistent with - or represent a warranted evolution of - the conceptual domains proposed by A\&B96. Similarly, the refinement in the conceptualisation of interactive controls proposed by Bisbe et al. (2007) introduces some extraneous meaning vis-à-vis the original formulation by Simons (1995). The introduction of extraneous meaning in the definitions of at least one of the categorisations creates conceptual divergence with earlier literature in each categorisation - and thus threatens conceptual clarity. Departures from the original formulations maybe the upshot of adaptations to new empirical contexts or the application of new theoretical insights (e.g. revision of the baseline properties of interactive systems in Bisbe et al., 2007, in an attempt to ensure consistency with their expected outcomes as described by 
LOC). For conceptual clarity to be maintained, researchers should disclose and theoretically justify such re-elaborations.

\subsubsection{Research questions under inclusion approaches}

As just indicated, inclusion approaches involve serious challenges to conceptual clarity. Each of the three points of ambiguity and divergence is particularly problematic under these approaches. Research adopting an inclusion approach to connect $\mathrm{C} / \mathrm{E}$ and $\mathrm{D} / \mathrm{I}$ can be fruitful only if researchers meet the challenges described above. To do so, inclusion approaches may address research questions that examine the relationships between categories in the higher-order categorisation of interest and their antecedents or consequences (see Figures $4 a$ and $4 b$ for an instance of generic research models under these approaches). In this setting, the connection between categorisations serves an auxiliary purpose, as it is meant not to test theory but rather to address issues of construct conceptualisation and operationalisation, as well as validity concerns (Libby, Bloomfield \& Nelson, 2003). For example, research adopting this approach can provide a new conceptualisation of $\mathrm{C} / \mathrm{E}$ that departs from the original formulation in A\&B96 to include issues regarding the frequency and intensity of information use and the extent and type of interaction across managerial levels. Analogously, researchers can adopt this approach to provide a new conceptualisation of D/I controls that departs from Simons (1995) to include issues bearing on the type of information provided to employees and their degree of autonomy (typical of $\mathrm{C} / \mathrm{E}$ controls). Figures $4 a$ and $4 b$ give some examples of research questions, including auxiliary ones, which can be addressed under inclusion approaches.

\section{INSERT FIGURES $4 a$ AND $4 b$ ABOUT HERE}

\subsubsection{Combinable categorisations}

Approaches 4 and 5 in Table 1 draw on $\mathrm{C} / \mathrm{E}$ and $\mathrm{D} / \mathrm{I}$ as two distinct typologies that are nevertheless complementary and combinable. For studies under these approaches (e.g. Adler \& Chen, 2011; Chenhall et al., 2010; Mundy, 2010), each typology points to distinct sets of properties. Once considered together, these sets of properties collectively describe concurrent facets of a single control issue or implication. Thus, instead of each categorisation being used separately to study different issues or implications at different organisational levels of a broader control situation (as under approach 1), and rather than re-conceptualising categorisations of controls so that categories of a lower-order one become dimensions of a higher-order one (as in inclusion approaches 2 and 3), studies within approaches 4 and 5 conjointly use the two 
categorisations to study one specific issue or implication at a given organisational level (see Figure 5 for their generic research model). What differentiates approach 4 from approach 5 is that in the former, one of the typologies is considered a design choice and the other is a style-of-use choice, whereas both typologies are considered to be styles-of-use choices in the latter.

INSERT FIGURE 5 ABOUT HERE

\subsubsection{C/E and D/I as two combinable typologies (one design, one styles-of-use)}

Under approach 4, studies conceptualise $\mathrm{C} / \mathrm{E}$ as design-driven and D/I as driven by stylesof-use (e.g. Chenhall et al., 2010; Tessier \& Otley, 2012). ${ }^{14}$ Both distinctions are combined to collectively define a control situation in terms of both design and styles-of-use. In doing so, this approach highlights the implications of a given management control situation when influenced by both MCSs design and styles-of-use. For example, Chenhall et al. (2010) combine C/E and D/I to understand the interplay between MCSs and social connections in organisations. As described in their study, MCSs are bureaucratic systems that can be designed with enabling or coercive characteristics. Hence, whether MCSs are coercive or enabling is a distinction based on a designdriven choice. Depending on how they are subsequently used, MCSs will behave as diagnostic or interactive controls. Therefore, at least in theory, systems designed with coercive characteristics can accommodate both diagnostic and interactive styles-of-use - and the same is true for systems designed with enabling characteristics. The distinction between diagnostic versus interactive controls refers to diverse styles-of-use of MCSs designed in a certain way. As the two categorisations are combined, diagnostic and interactive uses of MCSs are embedded within a bureaucratic system that has been designed with enabling or coercive characteristics (e.g. 'MCSs [can] be designed in ways to ensure that they are enabling and then be used in an interactive way' in Chenhall et al., 2010:753). The effects of coercive and enabling designs depend on whether these are implemented with a diagnostic or an interactive style-of-use. At the same time, and as stated by Chenhall et al. (2010), the effects of interactive and diagnostic styles-of-use depend on whether the MCSs being used have been designed with enabling or coercive capabilities. This approach resonates well with both the focus on autonomy arising from $\mathrm{C} / \mathrm{E}$ and the focus on patterns of attention stemming from $\mathrm{D} / \mathrm{I}$. The enabling/coercive design of the systems defines the

\footnotetext{
${ }^{14}$ There is some ambiguity in Tessier and Otley (2012) as to whether they see the distinction enabling/constraining as a design or a style-of-use attribute of MCSs (we interpret the term 'constraining' as equivalent to 'coercive'). Tessier and Otley disclose little about the properties of enabling and constraining systems. Although they explicitly state that this distinction is a design attribute of MCSs (Tessier \& Otley, 2012: 175), the inclusion of non-invasive, facilitating, and inspirational involvement by top managers as a characteristic of enabling systems hints at a style-of-use attribute.
} 
extent of employee autonomy, while the diagnostic/interactive styles-of-use of these systems defines the patterns of top management attention.

\subsubsection{2. $C / E$ and $D / I$ as two combinable typologies (both styles-of-use)}

Approach 5 in Table 1 conceptualises both $\mathrm{C} / \mathrm{E}$ and $\mathrm{D} / \mathrm{I}$ as driven by style-of-use choices (e.g. Adler \& Chen, 2011; Mundy, 2010). For papers in this fifth approach, a key thrust is that once an MCS is in place, managers make two choices on how the MCS will be used in the organisation: they can potentially opt for the system being used in an enabling or coercive manner, and they can potentially opt for the system being used in a diagnostic or interactive manner. Thus, no reference is made to design considerations, and both $\mathrm{C} / \mathrm{E}$ and $\mathrm{D} / \mathrm{I}$ refer to different facets of styles-of-use. For example, when Mundy (2010) stresses the importance of striking a balance between coercive ${ }^{15}$ and enabling uses of individual levers of control in the creation of dynamic tensions, she considers that diagnostic control systems can be used in both coercive and enabling manners; the same goes for interactive controls. Similarly, Adler and Chen (2011) refer to both 'coercive and enabling uses of diagnostic control systems'. In this context, as both frameworks define styles-of-use, 'a coercive [style-of] use of a diagnostic control system' is interchangeable with 'a diagnostic [style-of] use of a coercive MCS' and both can be reinterpreted as 'a [coercive and diagnostic][style-of]use of an MCS'. In contrast to the inclusion approaches 2 and 3 (where one of the two categorisations was lower-order and its categories were considered constitutive components of the other higher-order categorisation), in approach 5 the two styles-of-use categorisations are of the same order. Their combination results in the creation of a new and more complex higher-order style-of-use (e.g. coercive and enabling uses of interactive controls in Mundy (2010)). Using this approach implies that both the extent of employee attention and the patterns of top management attention are the joint result of the new higher-order style-of-use.

\subsubsection{Conceptual clarity in the combinatory approaches}

Divergence in perspective across categorisations (be it related to organisational position or to decision focus) may threaten conceptual clarity in combinatory approaches (see Table 2). As originally formulated, studies drawing on $\mathrm{C} / \mathrm{E}$ converge towards taking a middle and lower management and employee perspective and tend to focus on operational contents. In contrast, studies drawing on $\mathrm{D} / \mathrm{I}$ converge towards taking a senior management perspective and tend to focus on strategic contents. Whether MCSs in general are relevant to all levels of management

\footnotetext{
${ }^{15} \mathrm{We}$ interpret 'coercive' and 'controlling' in Mundy (2010) as interchangeable.
} 
and whether they facilitate the attainment of organisational objectives at both the operational and strategic level is not in question. Rather, the question here is how researchers see the two specific categorisations of interest so that - despite divergence across them - they can meaningfully be combined to conjointly address an issue or implication at a given organisational level. To this end, they need to match in terms of the position from which the analysis is undertaken and in terms of decision focus. The combination of the two categorisations assumes that they make sense of a phenomenon or a situation from the perspective of the same actors, and that there is a contact zone between the focus of decisions affected by the coercive versus enabling choice and the focus of decisions affected by interactive versus diagnostic choice.

Examples of adaptation or reinterpretation of the extant categorisations so that they share organisational position and decision focus can be found in several studies using a combinatory approach. A number of researchers (e.g., Frow et al., 2010; Mundy, 2010; Tessier \& Otley, 2012) have claimed that ideas on $\mathrm{D} / \mathrm{I}$ need not be confined to the perspective of top managers, but rather can be used to examine a phenomenon or a situation from the perspective of lower levels. Mundy (2010), for example, suggests that, although LOC was originally distilled from observations of top executives in large corporations, its relevance is not restricted to the highest levels of management, as line managers may play a crucial role in identifying and generating new initiatives and in using MCSs in different ways to achieve the organisation's objectives. Similarly, some studies drawing on $\mathrm{D} / \mathrm{I}$ consider that a focus on strategic decisions does not rule out decisions made by top managers and that these are affected by the levers of control and also involve some operational content, and thus expand the decision focus to include operational decisions. For instance, Mundy (2010:503:515) justifies this expansion by pointing out the relevance of the levers of control in helping implement organisational strategy as they allow managers to integrate operational and strategic concerns. Chenhall et al. (2010: 742) provide another example of such adaptation as the authors report their take on the original Simons' diagnostic control systems so that they can grasp the processes involved in employing MCSs at the operational level.

Whether categories are driven by design or by styles-of-use is not an issue for studies that conceptualise connections between frameworks under approach 4. This conceptualisation is undertaken fully respecting the generally accepted definitions of prior literature on each categorisation, namely the design-driven nature of $\mathrm{C} / \mathrm{E}$ and the style-of-use driven nature of D/I. ${ }^{16}$

\footnotetext{
${ }^{16}$ Even when that approach is adopted, it may be worth considering evolution and re-elaboration of the conceptual domains of some of the categories of interest in light of new empirical contexts or new theoretical insights. For example, researchers may explore revision of the baseline properties of D/I as described by Simons $(1995,2000)$ in order to ensure consistency with their expected implications and outcomes.
} 
This matter is more controversial for studies under approach 5. In this approach, researchers treat the $\mathrm{C} / \mathrm{E}$ distinction as a style-of-use choice instead of a design choice. Although this is not necessarily a blow to conceptual clarity, the combination of two typologies of styles-of-use requires a clear differentiation of the properties of the categories within each typology.

Considering the $\mathrm{C} / \mathrm{E}$ distinction as driven by styles-of-use implies that the properties that mark the distinction go beyond design features. If the properties that set coercive and enabling systems apart were all design-based, the distinction would not be a styles-of-use typology in itself and 'enabling use of diagnostic control systems' could be interpreted as 'diagnostic use of an MCS designed with enabling characteristics'. At the same time, if both typologies are seen as referring to styles-of-use, the styles-of-use properties of C/E should obviously be distinct from those of D/I. If both $\mathrm{C} / \mathrm{E}$ and $\mathrm{D} / \mathrm{I}$ are conceptualised as two complementary style-of-use typologies, special attention should be paid to clearly distinguishing the properties of the two categorisations of controls. Unfortunately, it is common for extant papers not to disclose or to be ambiguous about the specific styles-of-use properties - not driven by design - that differentiate coercive styles from enabling ones. Thus, while both Mundy (2010) and Adler and Chen (2011) are fairly transparent in detailing properties, implications and outcomes of D/I, they are less so when it comes to the defining features of coercive and enabling styles-of-use, which tends to lead to ambiguity and threatens clarity in the conceptualisation of the connections (Molloy \& Ployhart, 2012).

Most prior studies under approach 5 do not refer to A\&B96 design properties. For example, Mundy (2010) and Tessier and Otley (2012) focus more on the implications of C/E (e.g. mitigation of information asymmetry problems, reduction of uncertainty, promotion of creativity, and predictability) than on their properties. Defining coercive and enabling systems exclusively based on implications (rather than on properties) is problematic given that the implications of one concept are more likely to be shared with those of other concepts. For example, defining enabling controls on the basis of implications such as learning or empowerment risks blurring the construct's domain with those of neighbouring constructs with similar implications (e.g. feedforward controls and interactive controls). This raises the spectre of tautology, circularity, and overlap with other constructs. If new empirical contexts or new theoretical insights justify the adaptation of conceptual domains, the re-conceptualisation should centre on a clear definition of properties instead of implications or outcomes (Suddaby, 2010; Podsakoff et al., 2016).

\subsubsection{Research questions under combinatory approaches}

To address research questions investigating both patterns of top management attention and the degree of employee autonomy, approach 4 examines the joint effects of design features 
described by $\mathrm{C} / \mathrm{E}$ and of styles-of-use described by D/I. Both design features and style-of-use features combine to produce a certain implication at a given organisational level. Figure 6 provides a generic research model for approach 4 , with examples of accompanying research questions.

\section{INSERT FIGURE 6 ABOUT HERE}

Studies under approach 4 may draw on the Figure 6 generic research model to shed light on how the implications of diagnostic and interactive styles are influenced by coercive and enabling designs. This line of inquiry follows the path pursued by Chenhall et al. (2010) who show how the interactive use of formal controls assists in developing social capital if they have enabling characteristics. Studies under this approach may tell a story from the perspective of a manager who wants to use control systems to achieve some organisational goals. This manager is in a position in which she decides whether to use a performance measurement system (PMS) in a diagnostic or interactive manner. Hence, the control problem is approached from the perspective of the (higher) manager who makes conscious control choices on styles-of-use of MCSs. In line with the original formulation of D/I, implications (e.g. innovation, learning) and outcomes (e.g., business unit performance) are related to the achievement of organisational goals. The $\mathrm{C} / \mathrm{E}$ distinction may be brought into this story to capture whether and how the style-of-use effects are influenced by the degree of autonomy provided to organisational members through the MCS design. In this case, bringing in the $\mathrm{C} / \mathrm{E}$ distinction entails reinterpreting the perspective taken in the original A\&B96 C/E categorisation. Instead of taking the perspective of an employee, researchers could theorise about design choices purposefully made by managers and tell one coherent story. In our example, managers would not only decide on the style-of-use of the PMS, but also on the design aspects of that PMS in terms of repair, transparency, and so forth. This entails studying the intentions managers have with a certain PMS in relation to both design and use aspects.

However, intended use of control by management is not necessarily mirrored by how the managers' subordinates perceive the use of controls. Since the outcomes of control choices in terms of behaviour may strongly depend on the perceptions of those experiencing control, studying intended versus perceived control addresses different research questions. Therefore, researchers wanting to take a combinatory approach could alternatively start from the $\mathrm{C} / \mathrm{E}$ categorisation, adopting the employees' perspective. Hence, the control problem would be approached from how employees, who do not have a final say over the design of the MCS, perceive the characteristics of that system. A possible story taking this route could address the impact of a coercive PMS on 
innovative employee's behaviour. In this case, a reinterpretation of the perspective taken in D/I would be needed to translate the styles-of-use to the employee level. For example, styles-of-use could be studied not as deliberate management choices, but rather as employee perceptions on how their managers use the PMS. The main items of interest here are the implications and outcomes at the employee level caused by employee perceptions about PMS design and use by their managers.

Approach 5 is another version of combinatory approaches in which new more complex, and higher-order styles-of-use stem from the lower-order enabling, coercive, interactive, and diagnostic styles-of-use. The focus here is on the association between these higher-order stylesof-use and their potential implications. Thus, and in contrast to approach 2 , there is no interest in auxiliary research questions to establish how constructs of one categorisation can be conceptualised as dimensions of the other. The generic research model for approach 5 is identical to the one shown in Figure 6 except for the enabling versus coercive distinction being driven by style-of-use. As the interaction between the two typologies of styles-of-use can be interpreted as a styles-of-use typology on its own, the generic research model for approach 5 can also be represented as in Figure 7.

\section{INSERT FIGURE 7 ABOUT HERE}

The instances of research questions included in Figures 6 and 7 further indicate the potential of these models to examine which combinations work for the organisation as well as potential departures from predicted outcomes according to the original formulation of each categorisation of controls. Instances of such questions can be found, for example, in earlier literature investigating whether, as originally formulated by Simons (1995, 2000), diagnostic control systems are not positively associated with innovativeness and opportunity-seeking. In that respect, Adler and Chen (2011) argue that the lack of such positive association is not the result of the use of diagnostic control systems as such, but instead stems from the coercive form they often take. They posit that the use of diagnostic systems has positive or negative effects on motivation and innovation depending on whether they are used in an enabling or coercive manner. Analogously, while Simons $(1995,2000)$ establishes that interactive controls are positively associated with double-loop learning, innovativeness, and opportunity-seeking, Mundy (2010) shows that this is only the case if there is an enabling use of interactive controls. Studying the combination of both categorisations is thus a promising way to reconcile previously inconsistent findings and advance our knowledge on management control. 
Through these approaches, researchers can also look at the functionality of theoretically possible combinations. For example, can coercive systems be used interactively, or would this be a dysfunctional or non-sustainable combination? One could argue that the interactive style-of-use of systems designed with coercive characteristics is potentially problematic because there is a likely mismatch between a dialogic pattern of communication and design characteristics primarily concerned with compliance and fault avoidance. Along these lines, Chenhall et al. (2010) report in their study of the development of social connections in an NGO how the interactive use in staff discussions of budgeting systems designed with coercive characteristics created tensions around reactions to cost overruns and cost allocations, eventually leading to a dysfunctional breakdown in bonding. Along similar lines, Mundy (2010) describes a research site where a coercive use of interactive systems was initially present. Yet, as this provided no opportunity to debate and challenge objectives, priorities, and non-standard approaches, it was deemed as dysfunctional and eventually suppressed. In turn, Adler and Chen (2011) refer in their study to enabling and coercive uses of diagnostic control systems but do not do so for interactive controls. Nevertheless, the arguments in Adler and Chen (2011) in favour of interactive controls being associated with creativity seem to suggest little scope for their coercive use. Overall, these studies indicate that firms are unlikely to sustainably employ interactive controls in a coercive way. However, the extent to which it is feasible, sustainable, or functional to combine $\mathrm{C} / \mathrm{E}$ and $\mathrm{D} / \mathrm{I}$ characteristics in an MCS is still an open research question.

\section{Conclusion}

In recent years, interest has grown in drawing on Adler and Borys' (1996) (A\&B96) distinction between coercive and enabling systems (C/E), as well as on Simons' $(1995,2000)$ distinction between diagnostic and interactive systems (D/I) for studying management control situations. As the two pairs of concepts $\mathrm{C} / \mathrm{E}$ and $\mathrm{D} / \mathrm{I}$ have taken hold, a stream of literature has arisen that draws on both categorisations to tackle complex aspects of organisational life. An examination of studies that are informed by both $\mathrm{C} / \mathrm{E}$ and $\mathrm{D} / \mathrm{I}$ and establish connections between them indicates that these studies seek to answer research questions that involve both the degree of employee autonomy and patterns of top management attention. These studies suggest that connecting $\mathrm{C} / \mathrm{E}$ and $\mathrm{D} / \mathrm{I}$ is a potentially productive strategy for examining such research questions and furthering our understanding of the workings of MCSs, since each categorisation by itself would only yield a partial explanation. 
While there are many research opportunities in which drawing on both $\mathrm{C} / \mathrm{E}$ and $\mathrm{D} / \mathrm{I}$ could prove useful, it is not clear from earlier literature how to connect both categorisations in a conceptually clear manner. In this paper, we conduct an in-depth review of the literature drawing on both categorisations to assess the conceptual clarity of the connections between them and to give guidelines to further advance research in this stream. Our analysis of the literature reveals that, even if there is little conceptual ambiguity and divergence within each categorisation, there is considerable conceptual ambiguity and divergence across the two categorisations. The ambiguity and divergence across categorisations arise from three points: (1) the perspective from which the analysis is undertaken, which includes aspects related to the organisational position and aspects related to the decision focus of the analysis, (2) the consideration of the categories as design-driven choices or as a style-of-use choices; and (3) the properties defining the categories. An additional source of divergence is the variety of approaches adopted in the literature to specify the form of connection. We have identified five forms: one coexistence approach; two inclusion approaches; and two combinatory approaches.

Depending on the approach adopted to connect the categorisations, the three detected points of conceptual ambiguity and divergence manifest themselves differently and have different relevance in the quest for construct clarity. As summarised in Table 2, all approaches bring their own challenges to conceptual clarity. Key challenges for the coexistence approach are the theorisation of the dynamics of the interaction between perspectives, and the collection of empirical data on multiple angles from multiple sources. Inclusion approaches are likely to be problematic because of the introduction of extraneous meaning in the definitions of at least one of the categorisations. Under inclusion approaches, a key challenge for researchers is how to tackle the conceptual re-elaborations needed for convergence across categorisations without creating divergence within categorisations. Finally, combinatory approaches need to demonstrate consistency in the perspectives from which the analysis is undertaken in each of the two categorisations.

Despite these challenges, earlier research indicates that connecting $\mathrm{C} / \mathrm{E}$ and $\mathrm{D} / \mathrm{I}$ may be a valuable way of tackling research questions on complex control situations involving both the degree of employee autonomy and patterns of management attention. In this paper, we have stressed the importance of conceptual clarity for empirically examining such research questions. We provide guidance for future accounting research interested in drawing on both categorisations with a view to boosting conceptual clarity in the field. These guidelines should also help increase transparency and comparability among studies. In identifying alternative approaches to the forms of connection across categorisations, we further contribute by setting out for each approach some 
research opportunities that leverage the potential of connecting $\mathrm{C} / \mathrm{E}$ and $\mathrm{D} / \mathrm{I}$. Here, we give an inkling of the scope for reaching a more holistic understanding of control situations while striving for conceptual clarity. While the current paper is on conceptual clarity, we see it as located in the dialectics of scholarly progress by which clarification, consistency, and validity checks are in dynamic interplay with the refinement, revisions, and new meanings that emerge as researchers apply concepts to new empirical settings or encounter new methods or theories. It is in the context of this dialectic that our paper, which untangles the threads of the connections between $\mathrm{C} / \mathrm{E}$ and $\mathrm{D} / \mathrm{I}$, can help to push forward the frontiers of knowledge on the use of MCSs. 


\section{Acknowledgments}

The authors greatly acknowledge the contributions and comments that Chris Chapman, Roland Speklé, Breda Sweeney, Jeanette Willert and the participants to the $10^{\text {th }}$ Management Control Association Conference and to the $10^{\text {th }}$ Conference on New Directions in Management Accounting made to earlier drafts of the paper.

\section{Funding sources}

This research did not receive any specific grant from funding agencies in the public, commercial, or not-for-profit sectors. 


\section{References}

Papers indicated with $(*)$ are papers included in Figure 1.

(*)Abernethy, M. A., Bouwens, J., \& Van Lent, L. (2010). Leadership and control system design. Management Accounting Research, 21, 2-16. https://doi.org/10.1016/j.mar.2009.10.002.

(*)Abernethy, M. A., \& Brownell, P. (1999). The role of budgets in organizations facing strategic change: an exploratory study. Accounting, Organizations and Society, 24(3), 189-204. https://doi.org/10.1016/s03613682(98)00059-2.

Adler, P.S. (2005). The evolving object of software development. Organization, 12(3), 401-435. https://doi.org/10.1177/1350508405051277.

Adler, P.S. (2012). The sociological ambivalence of bureaucracy: from Weber via Gouldner to Marx. Organization Science, 23(1), 244-266. https://doi.org/10.1287/orsc.1100.0615.

(*)Adler, P.S. \& Borys, B. (1996). Two types of bureaucracy: enabling and coercive. Administrative Sciences Quarterly, 41(1), 61-89. https://doi.org/10.2307/2393986.

(*)Adler, P. S., \& Chen, X. (2011). Combining creativity and control: Understanding individual motivation in large-scale collaborative creativity. Accounting, Organizations and Society, 36(2), 63-85. https://doi.org/10.1016/j.aos.2011.02.002.

Adler, P.S., Goldoftas, B., \& Levine, D.I. (1999). Flexibility versus efficiency? A case study of model changeovers in the Toyota production system. Organization Science, 10(1), 43-68. https://doi.org/10.1287/orsc.10.1.43.

(*)Ahrens, T., \& Chapman, C. S. (2004). Accounting for flexibility and efficiency: a field study of management control systems in a restaurant chain. Contemporary Accounting Research, 21(2), 271-301. https://doi.org/10.1506/vjr6-rp75-7gux-xh0x.

(*)Arjaliès, D. L., \& Mundy, J. (2013). The use of management control systems to manage CSR strategy: A levers of control perspective. Management Accounting Research, 24(4), 284-300. https://doi.org/10.1016/i.mar.2013.06.003

(*)Bedford, D. S. (2015). Management control systems across different modes of innovation: Implications for firm performance. Management Accounting Research, 28, 12-30. https://doi.org/10.1016/j.mar.2015.04.003.

(*)Bedford, D.S., \& Malmi, T. (2015). Configurations of control: An exploratory analysis. Management Accounting Research, 27, 2-26. https://doi.org/10.1016/j.mar.2015.04.002.

$\left({ }^{*}\right)$ Bisbe, J., \& Malagueño, R. (2015). How control systems influence product innovation processes: examining the role of entrepreneurial orientation. Accounting and Business Research, 45(3), 356-386. https://doi.org/10.1080/00014788.2015.1009870.

(*)Bisbe, J., \& Malagueño, R. (2009). The Choice of Interactive Control Systems under Different Innovation Management Modes. European Accounting Review, 18(2), 371-405. https://doi.org/10.1080/09638180902863803.

(*)Bisbe, J., \& Otley, D. (2004). The effects of the interactive use of management control systems on product innovation. Accounting, Organizations and Society, 29, 709-737. https://doi.org/10.1016/j.aos.2003.10.010.

(*)Bisbe, J., Batista-Foguet, J-M., \& Chenhall, R. (2007). Defining management accounting constructs: a methodological note on the risks of conceptual misspecification. Accounting, Organizations and Society, $32(7-$ 8), 789-820. https://doi.org/10.1016/j.aos.2006.09.010.

Bonner, J. M., Ruekert, R. W., \& Walker, O. C. (2002). Upper management control of new product development projects and project performance. Journal of Product Innovation Management, 19(3), 233-245. https://doi.org/10.1111/1540-5885.1930233.

Bouwens, J., \& Abernethy, M. A. (2000). The consequences of customization on management accounting system design. Accounting, Organizations and Society, 25(3), 221-241. https://doi.org/10.1016/s0361-3682(99)000434.

(*)Bruining, H., Bonnet, M., \& Wright, M. (2004). Management control systems and strategy change in buyouts. Management Accounting Research, 15, 155-177. https://doi.org/10.1016/j.mar.2004.03.003.

Cardinaels, E. (2008). The interplay between cost accounting knowledge and presentation formats in cost-based decision-making. Accounting, Organizations and Society, 33, 582-602. https://doi.org/10.1016/j.aos.2007.06.003.

(*)Chapman, C.S., \& Kihn, L. (2009). Information system integration, enabling control and performance. Accounting, Organizations and Society, 34, 151-169. https://doi.org/10.1016/j.aos.2008.07.003.

Chenhall, R. (2007) 'Theorizing Contingencies in Management Control Systems Research'. In C. S. Chapman, A. G. Hopwood, \& M. D. Shields (Eds.) Handbook of management accounting research. Vol. 1 (pp. 163-205). Oxford: Elsevier.

(*)Chenhall, R. H., \& Moers F. (2015). The role of innovation in the evolution of management accounting and its integration into management control. Accounting, Organizations and Society, 47, 1-13. https://doi.org/10.1016/j.aos.2015.10.002. 
(*)Chenhall, R. H., Hall, M., \& Smith, D. (2010). Social capital and management control systems: a study of a non-government organization. Accounting, Organizations and Society, 35, 737-756. https://doi.org/10.1016/j.aos.2010.09.006.

(*)Chenhall, R. H., Kallunki, J-P, \& Silvola, H. (2011). Exploring the relationships between strategy, innovation, and management control systems: the roles of social networking, organic innovative culture, and formal controls. Journal of Management Accounting Research, 23, 99-128. https://doi.org/10.2308/jmar-10069.

Chenhall, R. H., \& Langfield-Smith, K. (1998). The relationship between strategic priorities, management techniques and management accounting: An empirical investigation using a systems approach. Accounting, Organizations and Society, 23(3). 243-264. https://doi.org/10.1016/s0361-3682(97)00024-X.

Chenhall, R. H., \& Morris, D. (1986). The impact of structure, environment and interdependencies on the perceived usefulness of management accounting systems. The Accounting Review, 61, 16-35.

(*)Chong, K. M., \& Mahama, H. (2014). The impact of interactive and diagnostic uses of budgets on team effectiveness. Management Accounting Research, 25(3), 206-222. https://doi.org/10.1016/j.mar.2013.10.008.

(*)Collier, P. M. (2005). Entrepreneurial control and the construction of a relevant accounting. Management Accounting Research, 16, 321-339. https://doi.org/10.1016/j.mar.2005.06.007.

(*)Cools, M., Emmanuel, C., \& Jorissen, A. (2008). Management control in the transfer pricing tax compliant multinational enterprise. Accounting, Organizations and Society, 33, 603-628. https://doi.org/10.1016/j.aos.2007.05.004.

(*)Cugueró-Escofet, N., \& Rosanas, J. M. (2013). The just design and use of management control systems as requirements for goal congruence. Management Accounting Research, 24(1), 23-40. https://doi.org/10.1016/j.mar.2012.11.001.

(*)Davila, T. (2000). An empirical study on the drivers of management control systems design in new product development. Accounting, Organizations and Society, 25(4-5), 383-410. https://doi.org/10.1016/s03613682(99)00034-3.

Davila, A., \& Foster, G. (2007). The adoption and evolution of management control systems in entrepreneurial companies: evidence and a promising future. In C. S. Chapman, A. G. Hopwood, \& M. D. Shields (Eds.) Handbook of Management Accounting Research. Vol. 3 (pp.1323-1336). Oxford: Elsevier.

(*)Davila, A., Foster, G., \& Li, M. (2009a). Reasons for management control systems adoption: Insights from product development systems choice by early-stage entrepreneurial companies. Accounting, Organizations and Society, 34(3-4), 322-347. https://doi.org/10.1016/j.aos.2008.08.002.

(*)Davila, A., Foster, G., \& Oyon, D. (2009b). Accounting and control, entrepreneurship and innovation: venturing into new research opportunities. European Accounting Review, 18(2), 281-311. https://doi.org/10.1080/09638180902731455.

(*)De Haas, M., \& Kleingeld, A. (1999). Multilevel design of performance measurement systems: enhancing strategic dialogue throughout the organization. Management Accounting Research, 10, 233-261. https://doi.org/10.1006/mare.1998.0098.

(*)De Harlez, Y., \& Malagueño, R. (2015). Examining the joint effects of strategic priorities, use of management control systems, and personal background on hospital performance. Management Accounting Research, 30, 217. https://doi.org/10.1016/j.mar.2015.07.001.

Dekker, H. C., Groot, T., \& Schoute, M. (2013). A balancing act? The implications of mixed strategies for performance measurement system design. Journal of Management Accounting Research, 25, 71-98. https://doi.org/10.2139/ssrn.962766.

Dowling, C., \& Leech, S.A. (2014). A Big 4 firm's use of information technology to control the audit process: How an audit support system is changing auditor behavior. Contemporary Accounting Research, 31(1), 230252. https://doi.org/10.1111/1911-3846.12010.

(*)Englund H., \& Gerdin, J. (2015). Developing Enabling Performance Measurement Systems: On the interplay between numbers and operational knowledge. European Accounting Review, 24(2), 277-303. https://doi.org/10.1080/09638180.2014.918517.

Elshandidy, T., Shrives, P. J., Bamber M., \& Abraham S. (2018). Risk reporting: a review of the literature and implications for future research. Journal of Accounting Literature, 40, 54-84. https://doi.org/10.1016/j.acclit.2017.12.001.

(*)Ferreira, A., \& Otley, D. (2009). The design and use of performance management systems: An extended framework for analysis. Management Accounting Research, 20, 263-282. https://doi.org/10.1016/j.mar.2009.07.003.

Fisher, J. G. (1995). Contingency-based research on management control systems: Categorization by level of complexity. Journal of Accounting Literature, 14, 24-49.

(*)Free, C. (2007). Supply-chain accounting practices in the UK retail sector: enabling or coercing collaboration? Contemporary Accounting Research, 24(3), 897-933. https://doi.org/10.1506/car.24.3.9. 
(*)Fried, A. (2010). Performance measurement systems and their relation to strategic learning: a case-study in a software developing organization. Critical Perspectives on Accounting, 21, 118-133. https://doi.org/10.1016/j.cpa.2009.08.007.

(*)Frow, N., Marginson, D., \& Ogden, S. (2010). “Continuous budgeting”: reconciling budget flexibility with budgetary control. Accounting, Organizations and Society, 35, 444-461. https://doi.org/10.1016/j.aos.2009.10.003.

Gerdin, J. (2005). Management accounting system design in manufacturing departments: an empirical investigation using a multiple contingencies approach. Accounting, Organizations and Society, 30(2), 99-126. https://doi.org/10.1016/j.aos.2003.11.003.

(*)Gond, J-P., Grubnic, S., Herzig, C., \& Moon, J. (2012). Configuring management control systems: theorizing the integration of strategy and sustainability. Management Accounting Research, 23, 205-223. https://doi.org/10.1016/j.mar.2012.06.003.

(*)Grabner, I., \& Moers, F. (2013). Management control as a system or a package? Conceptual and empirical issues. Accounting Organizations and Society, 38(6-7), 407-419. https://doi.org/10.1016/j.aos.2013.09.002.

Granlund, M., \& Taipaleenmaki, J. (2005). Management control and controllership in new economy firms - a life cycle perspective. Management Accounting Research, 16, 21-57. https://doi.org/10.1016/j.mar.2004.09.003.

(*)Groen, B., Wouters, M., \& Wilderom, C. (2012). Why do employees take more initiatives to improve their performance after co-developing performance measures? A field study. Management Accounting Research, 23(2), 120-141. https://doi.org/10.1016/j.mar.2012.01.001.

Hall, M. (2010). Accounting information and managerial work. Accounting, Organizations and Society, 35, 301315. https://doi.org/10.1016/j.aos.2009.09.003.

(*)Hartmann, F. G. H., \& Maas, V. S. (2011). The effects of uncertainty on the roles of controllers and budgets: an exploratory study. Accounting and Business Research, 41(5), 439-458. https://doi.org/10.1080/00014788.2011.597656.

(*)Henri, J. F. (2006). Management control systems and strategy: A resource-based perspective. Accounting, Organizations and Society, 31, 529-558. https://doi.org/10.1016/j.aos.2005.07.001.

Hirsch, P. M., \& Levin, D.Z. (1999). Umbrella advocates versus validity police: a life-cycle model. Organization Science, 10(2), 199-212. https://doi.org/10.1287/orsc.10.2.199.

Hopwood, A. G. (1972). An empirical study of the role of accounting data in performance evaluation. Journal of Accounting Research, 10 (Supplement), 156-182. https://doi.org/10.2307/2489870.

Hopwood, A. G. (1973).An Accounting System and Managerial Behaviour. London: Saxon House.

(*)Janke R., Mahlendorf, M. D., \& Weber, J. (2014). An exploratory study of the reciprocal relationship between interactive use of management control systems and perception of negative external crisis effects. Management Accounting Research, 25(4), 251-270. https://doi.org/10.1016/j.mar.2014.01.001.

(*)Jordan, S., \& Messner, M. (2012). Enabling control and the problem of incomplete performance indicators. Accounting, Organizations and Society, 37, 544-564. https://doi.org/10.1016/j.aos.2012.08.002.

(*)Jørgensen, B., \& Messner, M. (2009). Management Control in New Product Development: The Dynamics of Managing Flexibility and Efficiency. Journal of Management Accounting Research, 21, 99-124. https://doi.org/10.2308/jmar.2009.21.1.99.

(*)Kober, R., Ng, J., \& Paul, B. J. (2007). The interrelationship between management control mechanisms and strategy. Management Accounting Research, 18(4), 425-452. https://doi.org/10.1016/j.mar.2007.01.002.

(*)Kominis, G., \& Dudau, A. I. (2012). Time for interactive control systems in the public sector? The case of Every Child Matters policy change in England. Management Accounting Research, 23, 142-155. https://doi.org/10.1016/j.mar.2012.04.002.

Libby, R., Bloomfield, R., \& Nelson, M. (2002). Experimental research in financial accounting. Accounting, Organizations and Society, 27, 775-810. https://doi.org/10.1016/s0361-3682(01)00011-3.

Luft, J., \& Shields, M. D. (2003). Mapping management accounting: graphics and guidelines for theory-consistent empirical research. Accounting, Organizations and Society, 28, 169-249. https://doi.org/10.1016/s03613682(02)00026-0.

MacKenzie, S. B., Podsakoff, P. M., \& Podsakoff, N. P. (2011). Construct measurement and validation procedures in MIS and behavioural research: Integrating new and existing techniques. MIS Quarterly, 35(2), 293-334. https://doi.org/10.2307/23044045.

(*)Mahama, H., \& Cheng, M. M. (2013). The effect of managers' enabling perceptions on costing system use, psychological empowerment and task performance. Behavioral Research in Accounting, 25(1), 89-114. https://doi.org/10.2308/bria-50333.

Malmi, T., \& Brown, D. A. (2008). Management control systems as a package-Opportunities, challenges and research directions. Management Accounting Research, 19, 287-300.

https://doi.org/10.1016/j.mar.2008.09.003. 
(*)Marginson, D. E. W. (2002). Management control systems and their effects on strategy formation at middlemanagement levels: Evidence from a UK organisation. Strategic Management Journal, 23, 1019-1031. https://doi.org/10.1002/smj.271.

(*)Marginson, D., McAulay, L., Roush M., \& van Zijl, T. (2014). Examining a positive psychological role for performance measures. Management Accounting Research, 25(1), 63-75. https://doi.org/10.1016/j.mar.2013.10.002.

(*)Mikes, A. (2009). Risk management and calculative cultures. Management Accounting Research, $20,18-40$. https://doi.org/10.1016/j.mar.2008.10.005.

Molloy, J. C., \& Ployhart, R. E. (2012). Construct clarity: multidisciplinary considerations and an illustration using human capital. Human Resource Management Review, 22, 152-156. https://doi.org/10.1016/j.hrmr.2011.11.010.

(*)Mundy, J. (2010). Creating dynamic tensions through a balanced use of management control systems. Accounting, Organizations and Society, 35(5), 499-523. https://doi.org/10.1016/j.aos.2009.10.005.

(*)Naranjo-Gil, D., \& Hartmann, F. (2007). Management accounting systems, top management team heterogeneity and strategic change. Accounting, Organizations and Society, 32(7-8), 735-756. https://doi.org/10.1016/j.aos.2006.08.003.

(*)Naranjo-Gil, D., \& Hartmann, F. (2006). How top management teams use management accounting systems to implement strategy. Journal of Management Accounting Research, 18, 21-53. https://doi.org/10.2308/jmar.2006.18.1.21.

(*)Neu D., Rahaman A. S., \& Everett, J. (2014). Accounting and Sweatshops: Enabling Coordination and Control in Low-Price Apparel Production Chains. Contemporary accounting research, 31(2), 322-346. https://doi.org/10.1111/1911-3846.12026.

(*)Osborn, C. S. (1998). Systems for sustainable organizations: emergent strategies, interactive controls and semiformal information. Journal of Management Studies, 35(4), 481-509. https://doi.org/10.1111/1467$\underline{6486.00106 .}$

Otley, D. T. (1980). The contingency theory of management accounting: achievements and prognosis. Accounting, Organizations and Society, 5(4), 413-428. https://doi.org/10.1016/0361-3682(80)90040-9.

Podsakoff, P. M., MacKenzie, S. B., \& Podsakoff, N. P. (2016). Recommendations for creating better concept definitions in the organizational, behavioural and social sciences. Organizational Research Methods, 19(2), 159-203. https://doi.org/10.1177/1094428115624965.

(*)Rodrigue M., Magnan M., \& Boulianne, E. (2013). Stakeholders' influence on environmental strategy and performance indicators: A managerial perspective. Management Accounting Research, 24, 301-316. https://doi.org/10.1016/j.mar.2013.06.004.

(*)Simons, R. (1995). Levers of control. Boston: Harvard Business School Press.

(*)Simons, R. (2000). Performance measurement and control systems for implementing strategies. Upper Saddle River: Prentice Hall.

Simons, R. (2013). Performance measurement and control systems for implementing strategies. Pearson.

Spekle, R. F., \& Verbeeten, F. H. (2014). The use of performance measurement systems in the public sector: Effects on performance. Management Accounting Research, 25(2), 131-146. https://doi.org/10.1016/j.mar.2013.07.004.

(*)Su, S., Baird, K., \& Schoch, H. (2015). The moderating effect of organizational life cycle stages on the association between the interactive and diagnostic approaches to using controls with organizational performance. Management Accounting Research, 26, 40-53. https://doi.org/10.1016/j.mar.2014.09.001.

Suddaby, R. (2010). Construct clarity in theories of management and organization. Academy of Management Review, 35(3), 346-357. https://doi.org/10.5465/amr.35.3.zok346.

(*)Tessier, S., \& Otley, D. (2012). A conceptual development of Simons' Levers of Control framework. Management Accounting Research, 23, 171-185. https://doi.org/10.1016/j.mar.2012.04.003.

(*)Tuomela, T. S. (2005). The interplay of different levers of control: A case study of introducing a new performance measurement system. Management Accounting Research, 16 (3), 293-320. https://doi.org/10.1016/j.mar.2005.06.003.

(*)Widener, S. K. (2007). An empirical analysis of the levers of control framework. Accounting, Organizations and Society, 32, 757-788. https://doi.org/10.1016/j.aos.2007.01.001.

(*)Wouters, M., \& Roijmans, D. (2011). Using Prototypes to Induce Experimentation and Knowledge Integration in the Development of Enabling Accounting Information. Contemporary Accounting Research, 28(2), 708-736. https://doi.org/10.1111/j.1911-3846.2010.01055.x.

(*)Wouters, M., \& Wilderom, C. (2008). Developing performance-measurement systems as enabling formalization: a longitudinal field study of a logistics department. Accounting, Organizations and Society, 33, 488-516. https://doi.org/10.1016/j.aos.2007.05.002. 
Types of bureaucratic formalization

(coercive/ enabling)

Levers of Control categories

(diagnostic/ interactive)



Fig. 1. Classification of papers drawing on $\mathrm{C} / \mathrm{E}$ and $\mathrm{D} / \mathrm{I}$. 


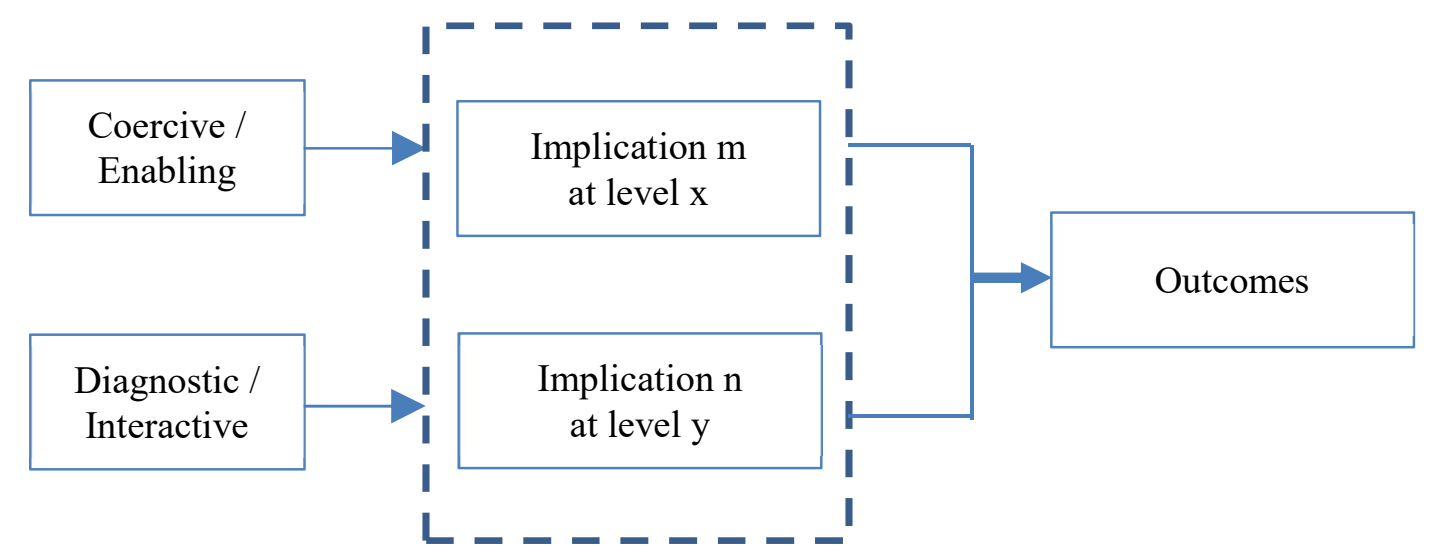

\section{Examples of research questions:}

- In what way is the interplay between the levers of control operating at top management levels intertwined with enabling systems operating at lower levels in order to ensure organizational learning?

- To what extent and how does reliance on interactive control systems in the ideation stage and on enabling systems in the development stage contribute to successful innovation outcomes?

- What characteristics of the control systems help promote focused top management attention (diagnostic/interactive) and employees' autonomy (enabling/coercive) so that strategic responses are more rapid and effective?

- In order to successfully implement innovative strategies, do firms rely on both interactive control systems for strategic decisions at top management and on enabling systems for operational decisions at lower levels?

- What are the implications for sustainable competitive advantage of relying on enabling systems to promote employee's empowerment while top-level managerial patterns of attention are diagnostic?

Fig. 2. Research models and instances of research questions for the coexistence approach. 


\begin{tabular}{|l|c|c|}
\hline & Diagnostic & Interactive \\
\hline $\begin{array}{l}\text { High use of financial MAS information } \\
\text { High use for performance evaluation }\end{array}$ & Coercive & \\
\hline $\begin{array}{l}\text { High use of non-financial MAS information } \\
\text { High use for resource allocation decisions }\end{array}$ & & Enabling \\
\hline
\end{tabular}

Fig. 3a. An example of conceptualization of diagnostic and interactive systems as constitutive dimensions of coercive and enabling systems.

\begin{tabular}{|c|c|c|}
\hline & $\begin{array}{c}\text { Coercive } \\
\text { (as invasive involvement) }\end{array}$ & $\begin{array}{c}\text { Enabling } \\
\text { (as non-invasive involvement) }\end{array}$ \\
\hline \multicolumn{3}{|l|}{$\begin{array}{l}\text { Attention by top and middle management } \\
\text { on an exception basis }\end{array}$} \\
\hline \multicolumn{3}{|l|}{$\begin{array}{c}\text { No need for face-to-face dialogic } \\
\text { communication }\end{array}$} \\
\hline \multicolumn{3}{|l|}{$\begin{array}{c}\text { Focus on critical performance variable } \\
\text { targets }\end{array}$} \\
\hline \multicolumn{3}{|l|}{$\begin{array}{c}\text { Permanent attention by middle and top } \\
\text { management (incl. top management } \\
\text { personal involvement) }\end{array}$} \\
\hline Face-to-face communication & & Interactive \\
\hline Focus on strategic uncertainties & & \\
\hline
\end{tabular}

Fig. 3b. An example of conceptualization of enabling systems as a constitutive dimension of interactive systems. 
Construct dimensions:

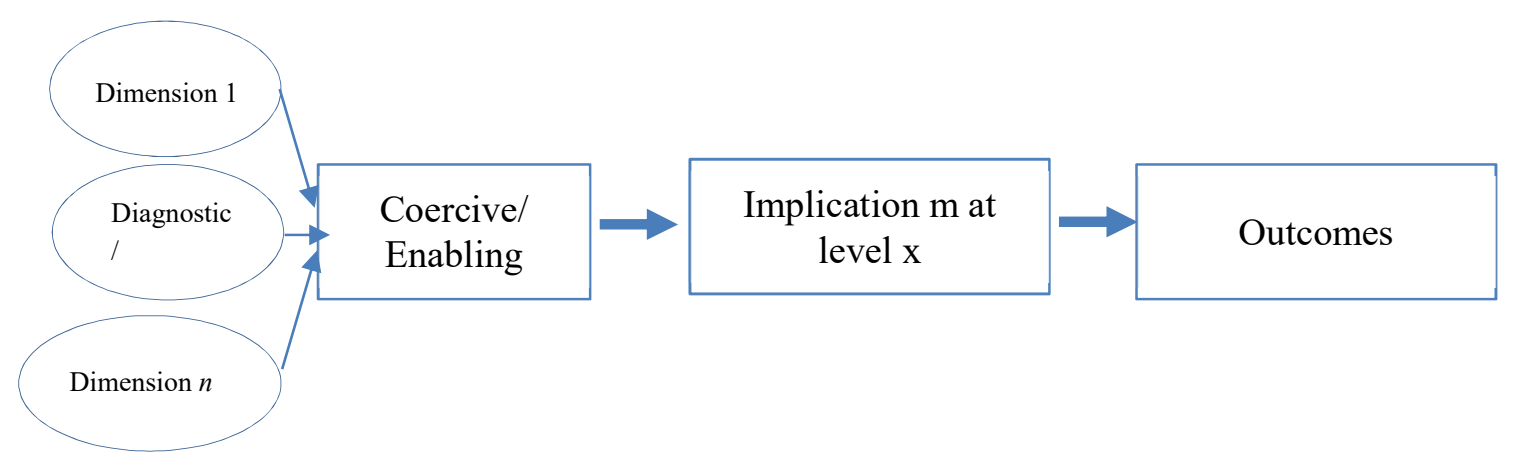

Examples of research questions:

- What is the effect of enabling systems on employees' empowerment?

- Auxiliary question: How to integrate the concepts diagnostic/ interactive into the definition of coercive/enabling in order to ensure validity of the latter?

- Auxiliary question: Is the conceptual domain of enabling systems properly defined if the distinction interactive vs. diagnostic is / is not considered in its definition?

Fig. 4a. Instance of generic research models and research questions under inclusion approaches. 




\section{Examples of research questions:}

- What is the effect of the interplay between diagnostic and interactive control systems on strategic change?

- Auxiliary question: How to integrate the concepts coercive/ enabling into the definition of diagnostic/ interactive systems in order to ensure validity of the latter?

- Auxiliary question: Is the conceptual domain of interactive control systems properly defined if the distinction enabling vs. coercive is / is not considered in its definition?

Fig. 4b. Instance of generic research models and research questions under inclusion approaches. 




Fig. 5. Generic research models for combinable categorizations. 




\section{Examples of research questions:}

- To what extent does the impact of interactive use of PMS on strategic speed depend on the design characteristics of the PMS being coercive or enabling?

- Does the impact of diagnostic use of PMS on effective strategy implementation depend on whether PMS are designed with coercive or enabling characteristics?

- Which configurations of control packages (including enabling versus coercive designs, diagnostic versus interactive styles-of-use) provide equilibrium states for a given context?

- To what extent does the impact of a control system designed with enabling characteristic on employee empowerment depend on the style of use (diagnostic versus interactive) of that system?

- How does the employee's autonomy provided by systems with enabling designs intertwine with the patterns of attention promoted by interactive control systems in order to make companies more adaptable to environmental changes?

- To what extent does a coercive PMS design impact on employee creativity when the PMS is being used diagnostically?

Fig. 6. Generic research model and instances of research questions for combinable categorizations (one design, one style of use). 


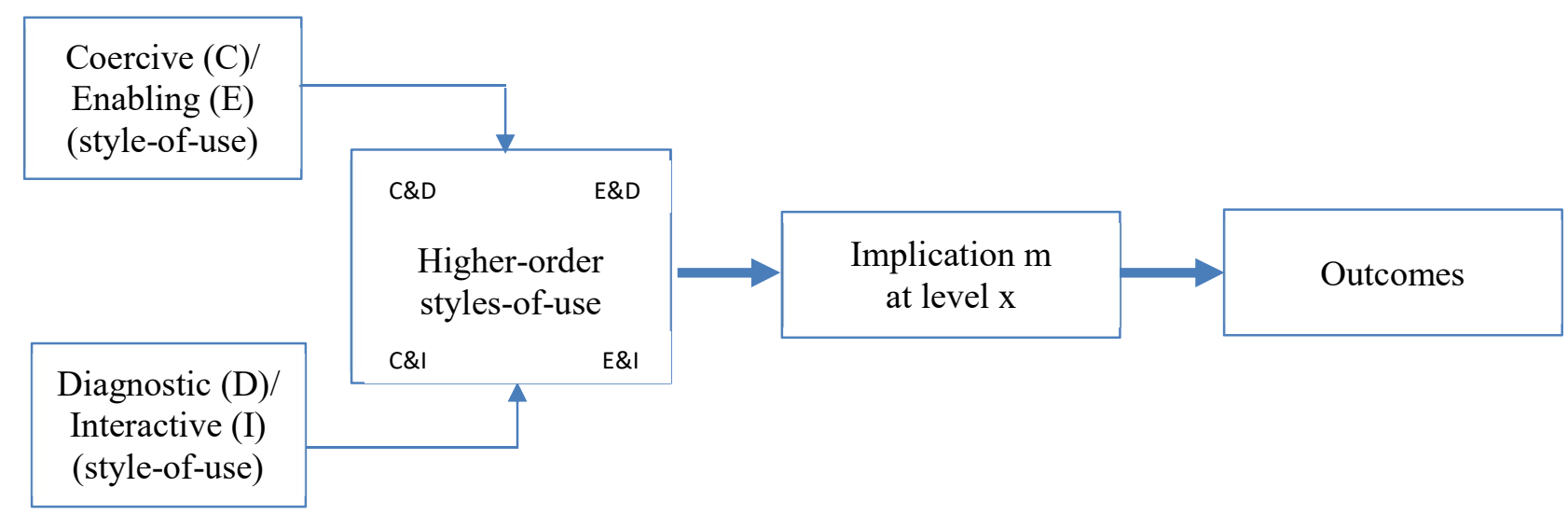

\section{Examples of research questions:}

- Is an enabling use of diagnostic control systems positively associated with intrinsic motivation?

- How do organizations balance controlling and enabling uses of interactive (and diagnostic) control systems to sustain organizational capabilities?

- Which configurations of control packages (including enabling, coercive, diagnostic, and interactive styles-ofuse) provide equilibrium states for a given context?

- How do coercive and enabling styles-of-use of MCS contribute to generating dynamic tensions between interactive and diagnostic styles-of-use?

- Is it feasible (or sustainable, or functional) to combine coercive and interactive characteristics in the style-ofuse of a control system?

- What is the influence of a coercive and diagnostic style-of-use on accountability?

Fig. 7. Generic research models and instances of research questions for combinable categorizations (both styles-of-use). 


\section{Table 1}

Approaches to the conceptualisation of the connections between the two categorisations.

\begin{tabular}{|c|}
\hline Coexisting categorisations \\
(1) $C / E$ and $D / I$ as two coexisting typologies \\
Inclusive categorisations \\
(2) $D / I$ as dimensions of $C / E$ \\
(3) C/E as dimensions of D/I \\
Combinable categorisations \\
(4) C/E and D/I as two combinable typologies (one design, one style-of-use) \\
(5) C/E and D/I as two combinable typologies (both styles-of-use) \\
\hline
\end{tabular}


Table $2^{\mathrm{a}}$

Points of ambiguity and divergence across categorisations under the different approaches to the forms of connection.

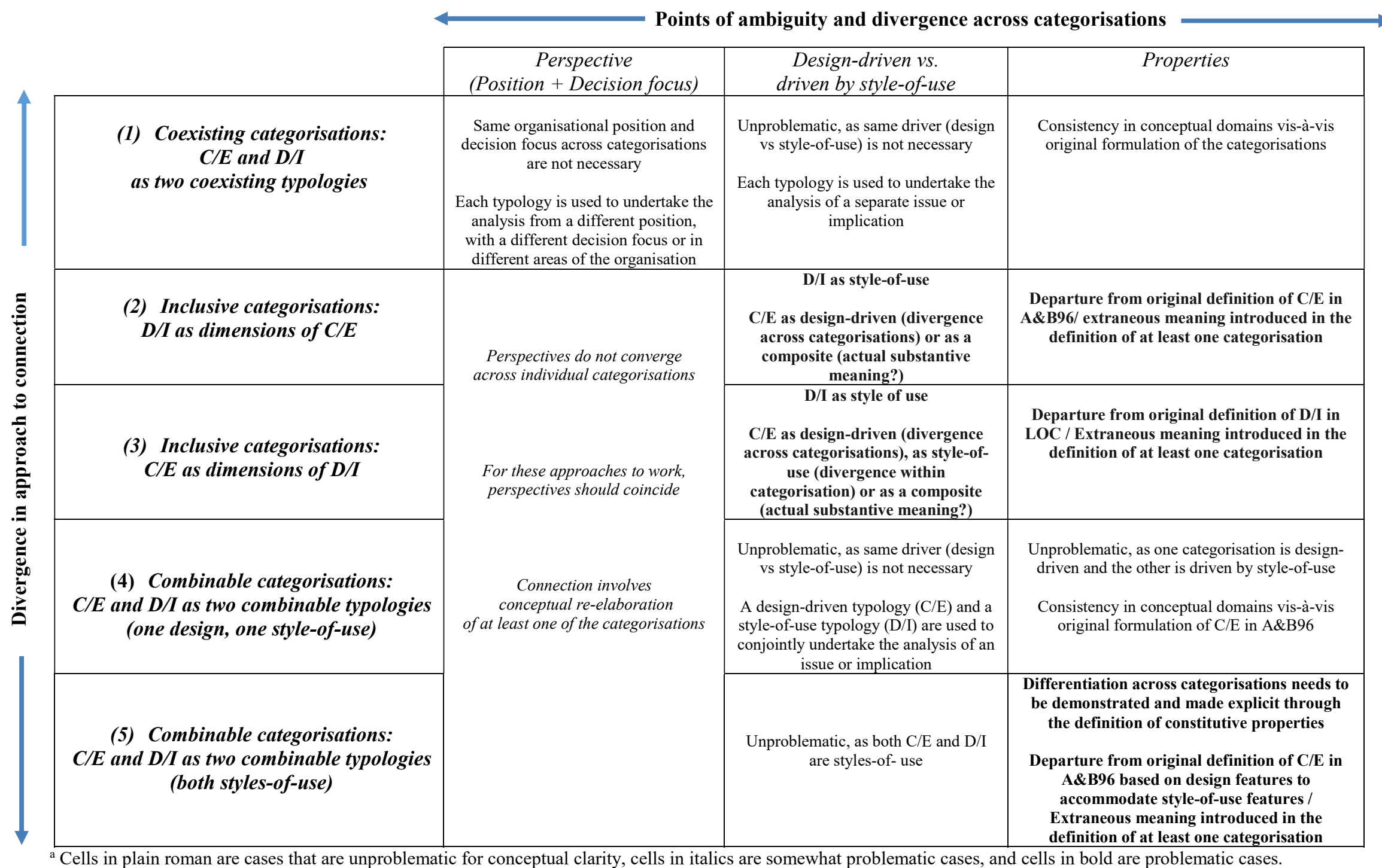

